Archimer, archive institutionnelle de l'Ifremer Vol. 268, Issues 1-4, 22 August 2007, Pages 106-122 http://dx.doi.org/10.1016/i.aquaculture.2007.04.033

\title{
Dietary neutral lipid level and source in marine fish larvae: effects on digestive physiology and food intake
}

\author{
S. Morais ${ }^{a^{*}}$, L.E.C. Conceição ${ }^{a}$, I. Rønnestad ${ }^{b}$, W. Koven ${ }^{c}$, C. Cahu ${ }^{d}$, J.L. Zambonino \\ Infante ${ }^{d}$, and M.T. Dinis ${ }^{a}$ \\ ${ }^{a}$ CCMAR, Universidade do Algarve, Campus de Gambelas, 8005-139 Faro, Portugal \\ ${ }^{\mathrm{b}}$ Department of Biology, University of Bergen, Allégt 41, N-5007 Bergen, Norway \\ ${ }^{c}$ Israel Oceanographic and Limnological Research, The National Centre for Mariculture, P.O. Box \\ 1212, Eilat 88112, Israel \\ d IFREMER, Station de Brest, Technopôle de Brest-Iroise, B.P. 70, 29280 Plouzané, France \\ * Corresponding author: Sofia Morais, CCMAR, Universidade do Algarve, Campus de Gambelas, \\ 8005-139 Faro, Portugal \\ Phone: +351- 289800100 \\ Fax: +351- 289818353 \\ Email: smorais@ualg.pt
}

\begin{abstract}
:
A growth depressing effect of high dietary neutral lipid levels in marine fish larvae has been reported. This may be a result of a decrease in the efficiency or activity of digestive enzymes, a reduction in absorption efficiency and/or a decrease in food intake. The present work reviews recent studies carried out on commercially valuable species (Atlantic herring, Senegalese sole, European seabass and gilthead seabream) that investigated the effects of neutral lipid level and lipid source (fatty acid composition) on some of these key factors influencing larval growth. The results seem to collectively indicate that lipid transport from the enterocytes into the body may be more problematic in larval stages dealing with high neutral lipid diets than lipolytic enzymatic capacity, although both factors are likely to intervene. In seabass, lipase activity was significantly affected by the source of dietary lipid but not by its dietary level. Lipid sources differing in chain length and degree of saturation of their fatty acids may thus affect the efficiency or synthesis of neutral lipase through effects on substrate specificity. Phospholipid digestion appears to be more efficient than that of neutral lipids, although neutral lipase synthesis might not be a limiting factor for larval growth. High neutral lipid larval diets result in the accumulation of large lipid droplets in the enterocytes, which may in turn reduce fatty acid absorption efficiency and ultimately larval growth. Nonetheless, not all fatty acids are equally affected and mechanisms of specific essential fatty acid absorption probably exist. Food intake in seabream larvae is not strictly regulated by total lipid content of the diet and lipid source may have an important role in controlling ingestion. Therefore, the neutral lipid level in diets for marine fish larvae has a significant impact in several factors influencing growth but clearly it cannot be dissociated of its fatty acid composition, which appears to play a central role on the nutritional and physiological effects of dietary lipid, at the ingestion, digestion and absorption levels.
\end{abstract}

Keywords: lipid quantity; fatty acid composition; absorption; digestion; lipid droplets; ingestion 


\section{Introduction}

Due to the importance of dietary lipid utilization in larval rearing, increasing attention has been paid to different aspects of larval lipid nutrition. In particular, the requirements for essential fatty acids (EFA) and their effects on growth and development have been extensively studied in marine fish larvae (Rainuzzo et al., 1997; Sargent et al. 1997, 1999). Relatively fewer studies have examined the effect of total lipid levels in larval diets and aspects such as digestion, absorption, transport and metabolism of dietary fatty acids (FA) have only started to be investigated in fish larvae (Izquierdo et al., 2000).

The attempt to meet larval requirements using poor sources of EFA, which are predominantly neutral lipids, necessitates increasing dietary percentages to potentially excessive levels that may also result in an imbalance in the neutral/polar lipid ratio. In fact, a number of authors have reported poor larval growth associated with a high lipid content of the diet (Kjørsvik et al., 1991a; Hoehne, 1999; Pousão-Ferreira et al., 1999; Izquierdo et al., 2000; Olsen et al., 2000a; Gawlicka et al., 2002). Different explanations have been proposed but the exact mechanisms behind these observations have not been completely clarified. Several effects of high dietary neutral lipid levels which may have a potential negative influence on larval growth can be suggested: at the digestion and absorption level, assuming that a high dietary lipid content may eventually result in a lower digestive efficacy or decreased activity of digestive enzymes and in a reduced absorption efficiency; and at the ingestion level, if a lipid-rich diet results in a lower food and thus protein intake (i.e., if a mechanism of regulation of food intake according to dietary energy level exists in larvae, as in juvenile and adult fish). The present work reviews studies carried out on commercially valuable species (Atlantic herring, Senegalese sole, seabass and seabream) that investigated the effects of neutral lipid level and lipid source on key factors influencing larval growth.

\section{Larval digestive capacity}

Lipid digestion, absorption and transport have been relatively poorly studied in fish, particularly in fish larvae. However, parallels have been found between the digestive and absorptive processes of fish and mammals and it is presumed that the mechanisms are generally similar (Sire et al., 1981; Honkanen et al., 1985). Briefly, dietary triacylglycerol (TAG) is partially hydrolysed to free fatty acids (FFA) and monoacylglycerol (MAG) or completely hydrolysed to FFA and glycerol by pancreatic lipase in the gut lumen (Tocher and Sargent, 1984; Lie et al., 1987; Gjellesvik, 1991; Koven et al., 1994a). The products of lipolysis are emulsified with bile components, forming mixed micelles, and the products of lipid digestion then diffuse into the intestinal mucosa cells, where they are mostly reesterified into TAG, before being incorporated into chylomicrons or very low density lipoproteins (VLDL) which are then released into the circulatory system (Noaillac-Depeyre and Gas, 1974; Sire et al., 1981; lijima et al., 1990).

A poor knowledge of the morphological and functional development of the larval digestive system, together with insufficient information on larval nutritional needs may partly explain the limited success of the intensive culture of marine fish (Kjørsvik et al., 1991b). Fish larvae are characterized by dietary requirements and digestive systems that differ from that of adults (Govoni et al., 1986). For instance, not only the enzymatic capacity but also the mechanisms of regulation of the pancreas seem to differ between larvae and adults (Kurokawa and Suzuki, 1996). It was originally believed that marine fish larvae have a poorly developed digestive system and immature digestive mechanisms, which has been used to explain the nutritional problems in rearing fish larvae, particularly on artificial diets (Lauff and Hofer, 1984; Walford and Lam, 1993). The larval gastrointestinal tract, although functional, in that it can process wild prey at first feeding, lacks a stomach and remains structurally and functionally less complex than in adults. This lower complexity was often associated with a lower digestive enzyme production (Govoni et al., 1986; Rust, 2002). Nonetheless, in most species, digestive enzymes are present at the onset of exogenous feeding (Cousin et al., 1987; Izquierdo et al., 2000; Hoehne-Reitan et al., 2001a) and several studies have found significant levels of pancreatic and intestinal enzymes and nutrient absorption capacities in fish larvae (Pedersen et al., 1987; Loewe and Eckman, 1988; Kjørsvik et al., 1991b; Segner et al., 1994; Ribeiro et al., 1999a,b). In addition, the liver, pancreas and gall bladder are differentiated at hatching and are functional before first feeding in many fish species (Govoni et al., 1986; Boulhic and Gabaudan, 1992; Segner et al., 1994; Kurokawa and Suzuki, 1996; Ribeiro et al., 1999a). The ultrastructural characteristics of the enterocytes of pre-feeding turbot and of 
coregonid larvae were described as being essentially the same as in adult fish (Loewe and Eckman, 1988; Segner et al., 1994) and the existence of functional lipid absorption structures, such as well developed endoplasmatic reticulum (ER) and Golgi apparatus at the time of first feeding has been noted for seabass and turbot larvae (Deplano et al., 1991; Segner et al., 1994). Therefore, there are strong indications that the enterocytes are not only cytologically differentiated but also physiologically functional at first feeding and that in the subsequent stages of ontogenetic development the intestine experiences mainly quantitative changes, such as an increase of length and mucosal surface area, as well as an intensification of the activities of brush border enzymes (Segner et al., 1994). Morphological observations of the digestive tract in cod larvae have shown that they are able to absorb ingested food before complete absorption of yolk reserves, with the foregut and particularly the midgut being quite active in lipid absorption (Kjørsvik et al., 1991b). In the Senegalese sole, Solea senegalensis, and in Dover sole, Solea solea, signs of intestinal absorption are visible after 3 days of exogenous feeding or just after first feeding, respectively, with several vacuoles of neutral lipids being observed in the anterior intestine (Ribeiro et al., 1999a) and in the midgut (Boulhic and Gabaudan, 1992).

Very little is known regarding the development of lipase activity during larval ontogeny. In red drum, lipase specific activity was detectable at hatching, peaked at 3 days after hatching (DAH), just prior to first feeding, and subsequently decreased (Lazo et al., 2000). Similarly, Hoehne-Reitan et al. (2001a) noted that bile salt-dependent lipase (BSDL) is present in turbot immediately after hatching and increased at the time of first feeding. Lipase activity was also detected as early as 2 DAH (first feeding) in the brush border and cytoplasm of enterocytes of Senegalese sole (Ribeiro et al., 1999a). In gilthead seabream larvae, BSDL activity was detected at first feeding and was seen to increase significantly during the first days of larval development (Izquierdo et al., 2000).

There are thus strong indications that fish larvae are capable of efficiently digesting and absorbing lipids from the start of exogenous feeding. However, there is very little information concerning the maximal digestive and absorptive capacity for lipids and FA in marine fish larvae (Planas and Cunha, 1999). A study was conducted with Atlantic herring (Clupea harengus L.) larvae which aimed at better understanding the mechanisms underlying and limiting lipid digestion and absorption in this species (Morais et al., 2005a). A visual description of the actions taking place in the gut during the passage of a pure neutral lipid (triolein, TRI) was made through video-tape analysis and showed that Atlantic herring was able to process the tube fed lipid, both through mechanical and chemical action. Contractions of the midgut wall caused the mechanical breakdown of large lipid droplets, an active dispersion and emulsification throughout the midgut (Fig. 1), and they most probably insured considerable mixing between the lipid droplets and the bile salts and pancreatic secretions being released close to the anterior midgut sphincter (Pedersen, 1984). As the mass of the lipid droplets moved to the posterior midgut, strong retrograde contractions of the midgut and hindgut likely increased the retention time in the gut and also allowed a better emulsification and mixing. Signs of chemical degradation during lipid digestion were also noted. For instance, the existence of smaller lipid droplets that do not fuse back together can be taken as a sign of the presence of bile salts in the gut lumen. In addition, the gradual change in the appearance of the lipid droplets, from a translucent and clear to an opaque and whitish look, was most probably the result of chemical mechanisms occurring during digestion.

The digestive and absorptive efficiency of tube fed ${ }^{14} \mathrm{C}$-TRI and of the FFA that it is comprised of, ${ }^{14} \mathrm{C}$-oleic acid (OA), was also examined in Atlantic herring (Morais et al., 2005a). Additionally, different volumes of ${ }^{14} \mathrm{C}$-TRI were tube fed to the larvae, in order to study the effect of lipid dose on digestive capacity. At a comparable volume (50.6 $\mathrm{nl}$ of tube fed lipid), OA, which does not require digestion, was significantly less evacuated and better absorbed than TRI (Fig. 2). However, a somewhat higher absorption and lower evacuation of TRI compared to OA was measured by reducing the volume of tube fed TRI from $50.6 \mathrm{nl}$ to $9.2 \mathrm{nl}$ (Fig. 2). Several authors have suggested that the absorption efficiency improves at a lower ration, through an increase in the residence time of food particles (Werner and Blaxter, 1980; Ryer and Boehlert, 1983; Boehlert and Yoklavich, 1984; Hoehne-Reitan et al., 2001b), which may have also been the case here. The metabolic studies, together with the video image analysis, suggested that the high dose of TRI may be too large for the enzymes to hydrolyze efficiently, which explains the increase in absorption at lower doses. Nevertheless, an inadequate digestive capacity could not fully explain the results, as higher doses of OA were slightly less absorbed than $9.2 \mathrm{nl}$ of TRI, suggesting that there is also likely an absorption efficiency component. 


\section{Dietary stimulation of lipase activity}

In the larvae of fish species studied so far, the exocrine pancreas is functional and pancreatic and intestinal enzyme activity is detected before first feeding, which suggests that enzymatic capacity is not induced by the diet (Ribeiro et al., 1999ab; Hoehne-Reitan et al., 2001a; Zambonino Infante and Cahu, 2001). Therefore, as in mammals (Henning, 1987), the temporal pattern of development is genetically determined, at least in the early stages. In turbot larvae, for instance, BSDL activity appears to follow an ontogenetically programmed pattern of development during the initial larval period, up to $5 \mathrm{DAH}$, while a dietary effect started to be noticeable at $7 \mathrm{DAH}$, when the BSDL content increased exponentially in fed larvae and decreased in starved larvae (Hoehne-Reitan et al., 2001a).

Nevertheless, relatively few studies have examined the influence of dietary composition on the regulation of digestive enzymatic activities, gastrointestinal tract function and development in fish, even though diet quality appears to have a direct effect on the onset of the maturation processes of the digestive tract (Cahu et al., 1995). In particular, dietary lipids have been observed to induce an earlier maturation of enterocytes in sea bass (Zambonino Infante and Cahu, 1999) and red drum larvae (Buchet et al., 2000). Studies looking at the quantitative lipid supply in marine fish larvae have described a stimulation of the lipolytic activities of pancreatic lipase and phospholipase $A_{2}$ by an increase in their substrate level in the diet, until a plateau is attained (Zambonino Infante and Cahu, 1999; Buchet et al., 2000). The existence of these plateaus of lipolytic enzyme expression thus suggests that there is a maximal capacity for enzyme synthesis (Buchet et al., 2000; Zambonino Infante and Cahu, 1999, 2001). This might have also been the case in Morais et al. (2005a), where the high TRI level was possibly beyond the plateau of enzymatic capacity of the Atlantic herring larvae. A complete and thorough review of aspects related to the ontogenetic changes and the role of diet in the development of larval gastrointestinal tract can be found in Cahu and Zambonino Infante (2001) and in Zambonino Infante and Cahu (2001).

The quality of the dietary lipid source is also an important parameter that may affect gastrointestinal tract development and digestive enzyme activity, although few studies have focused on this. TAG are generally the quantitatively most important lipid class in fish diets and their constituent FA composition, in terms of carbon chain length and degree of saturation, has been shown to affect digestion and absorption (Austreng et al., 1979; Linscheer and Vergroesen, 1994; Koven et al., 1994b; Olsen et al., 1998). Izquierdo et al. (2000) reported that neutral lipase activity is influenced by the FA composition of dietary lipids, as seabream larvae showed an increased lipase activity when they were fed rotifers containing TAG rich in 20:5n-3 instead of monounsaturated FA (MUFA).

In order to investigate these aspects further, a study was conducted in which the influence of dietary TAG source (fish oil, triolein and coconut oil) and level ( $7.5 \%$ and $15 \%$ of the diet) on growth and lipase activity was studied in seabass (Dicentrarchus labrax L.) larvae, from mouth opening until $24 \mathrm{DAH}$ and from 37 to $52 \mathrm{DAH}$ (Morais et al., 2004a). In this experiment, the source of dietary lipid, but not the quantity, was shown to significantly affect lipase activity. Coconut oil diets induced a high lipase activity both at 24 and 52 DAH while the effect of fish oil was age dependent - although similar to coconut oil at $24 \mathrm{DAH}$, it induced the lowest lipase activity in $52 \mathrm{DAH}$ larvae (Fig. 3). The differential lipase activity in larvae fed different diets was probably due to differences in the FA composition of the treatment diets. The FA specificity of lipolytic enzymes has been relatively well studied and the effects of FA on the activity of pancreatic lipase are related to both the acyl chain length and degree of saturation (Brannon, 1990; Linscheer and Vergroesen, 1994). In fish, the digestibility of FA has been shown to decrease with increasing chain length and to increase with unsaturation (Austreng et al., 1979; Olsen et al., 1998; Morais et al., 2005b). Fish lipases have a preference for polyunsaturated FA (PUFA) as substrates, followed by MUFA, with saturated FA (SFA) being more resistant to lipolysis (Lie and Lambertsen, 1985; Gjellesvik, 1991; Koven et al., 1994b; lijima et al., 1998; Olsen et al., 1998). For this reason, fish oils commonly have high digestibility, while vegetable oils containing MUFA and particularly SFA show a more reduced digestibility. Therefore, the results obtained for seabass fed the coconut oil diets suggest that lipolytic activity might be stimulated by the medium chain FA (MCFA) and/or SFA (mainly 12:0 and 14:0) present in coconut oil. More than half of the coconut oil SFA are of the MCFA-type, which have the advantage of being rapidly and completely digested, even in the absence of bile salts, requiring minimal pancreatic lipase activity (Bach and Babayan, 1982). TAG containing $<12$ carbon FA can even be absorbed without hydrolysis (Bach and Babayan, 1982). Medium chain triacylglycerols (MCT) replacing fish oil in the diets of adult Atlantic salmon improved lipid digestibility by $3 \%$ and increased the pancreatic proteolytic activity of the chyme. Lipolytic activity was also slightly enhanced, although not significantly (Nordrum et al., 2000). 
In addition, the digestibility of coconut oil has been analysed in Arctic charr and 12:0 was found to be a good substrate for intestinal lipase, the lipolysis of 14:0 being intermediate (Olsen et al., 1998). The results obtained with the fish oil and triolein diets at 24 DAH reveal the same tendency as that reported by Izquierdo et al. (2000), that is, a higher lipase activity in larvae fed a PUFA-rich fish oil diet, compared to the MUFA-rich triolein diet. Nevertheless, the marked decrease in enzymatic activity caused by the fish oil diet at $52 \mathrm{DAH}$, particularly at the higher inclusion level (Fig. 3), was unexpected. The fish oil diet was characterized by a high level of PUFA, for which lipase has maximal specificity (Olsen et al., 1998). Nevertheless, it also contained the highest levels of several long chain MUFA and of the SFA 16:0, which have been reported to be more resistant to hydrolysis and absorption (Austreng et al., 1979; Lie and Lambertsen, 1985; Koven et al., 1994b). The agedependence of the physiological digestive response to the fish oil-based diets remains unresolved and should be the focus of further studies, as not only nutritional requirements but also digestive function may show important changes between early larvae and later larval/juvenile stages. It can be speculated that the long term feeding of seabass larvae with more digestible diets containing long chain FA, such as those using fish oil, cause an adaptative response leading to a lower secretion of pancreatic lipolytic enzymes. On the contrary, in a dietary regime containing less digestible oils, an elevated lipolytic activity would be maintained. The results obtained with seabass thus suggest the existence of a regulatory mechanism of neutral lipolytic enzyme secretion and activity according to the dietary FA composition in marine fish larvae, even if the understanding of the underlying mechanisms controlling such an adaptation is still scarce.

Total dietary lipid content has been reported to stimulate lipolytic enzymes both in mammals (Wicker and Puigserver, 1989; Brannon, 1990; Spannagel et al., 1996) and in fish, including seabass (Borlongan, 1990; Zambonino Infante and Cahu, 1999). Nonetheless, in Morais et al. (2004a), the increase in dietary lipid level was not found to affect lipase specific activity in seabass, possibly since the differences in total dietary lipid level (17\% and $24 \%)$ were not as marked as in Zambonino Infante and Cahu (1999), in which significant differences were only found between the dietary groups containing $10 \%$ lipids and $>20 \%$ lipids. Moreover, the low lipid level was close to the plateau of $20 \%$, over which there was no further stimulation of lipase activity (Zambonino Infante and Cahu, 1999). Additionally, it has been suggested that the intestinal receptors for intraluminal stimulants require only a very low concentration for activation, meaning that the length of the intestine exposed to these products is the main determinant of pancreatic secretory response (Singer, 1987). If this is the case in marine fish larvae, the ingestion rate of the diet may also play a major role in determining lipase activity. In accordance with this theory, Hoehne-Reitan et al. (2001b) showed that the BSDL content of turbot larvae was not significantly affected by the lipid level of the prey but appeared to be a function of the ingestion rate.

Endocrine factors may also be quite important in mediating a lipase activity response to dietary FA level and composition but, so far, have not been examined in fish. Dietary lipid has been shown to influence the release of cholecystokinin (CCK) and secretin, which are gastrointestinal hormones implicated in the stimulation of pancreatic enzyme secretion (Singer, 1987; Brannon, 1990; Spannagel et al., 1996). In addition, the chemical nature of the FA, particularly their carbon chain length, is known to affect CCK secretion in humans and other mammals, although the results obtained by various authors with diverse species reveal that different animals may show a discriminatory sensitivity to different FA (Hopman et al., 1984; Douglas et al., 1990; Matzinger et al., 2000). For instance, in humans MCT are a weaker stimulus to CCK secretion than long chain TAG (Hopman et al., 1984; Matzinger et al., 2000) while in rats MCT were found to be the most potent stimulators of CCK secretion (Douglas et al., 1990). A stimulatory role on the relative synthesis of lipase has also been described for secretin, whose plasma level increases in response to the products of lipid digestion (Brannon, 1990). In fish, evidence is starting to accumulate that CCK has the same functions as in mammals, namely in the stimulation of pancreatic enzyme secretion and bile release (gallbladder contraction) (Aldman et al., 1992; Holmgren, 1993; Aldman and Holmgren, 1995; Einarsson et al., 1997), in slowing down gastric emptying (Holmgren, 1993; Olsson et al., 1999) and in the control of food intake (Himick and Peter, 1994; Gélineau and Boujard, 2001). CCK producing cells have been identified in larval stages of several fish (García-Hernandez et al., 1994; Reinecke et al., 1997; Kurokawa et al., 2000; Kamisaka et al., 2001, 2002ab, 2003). In Japanese eel (Anquilla japonica) larvae, CCK mRNA was expressed in the larval intestine at the onset of exogenous feeding and it is hypothesized that CCK controls pancreatic enzyme secretion from first feeding (Kurokawa et al., 2004). There are thus indications that CCK participates in the regulation of the digestion of larval stages of Japanese eel, Atlantic halibut, Atlantic herring and European seabass (Koven et al., 2002; Rojas-García and Rønnestad, 2002; Cahu et al., 2004; Kurokawa et al., 2004). However, except for 
preliminary work on the CCK-mediated stimulation of pancreatic secretion by proteins and amino acids (AA) (Koven et al., 2002; Rojas-García and Rønnestad, 2002; Cahu et al., 2004), the adaptation of pancreatic secretion to dietary components, specifically lipids, remains completely unknown in fish.

In the study by Morais et al. (2004a), seabass growth was affected both by dietary lipid source and level; it was higher for the fish oil and triolein diets and was increased at the higher lipid level (except for the coconut oil diet in which a high supply of MCT may have had deleterious effects). Growth was thus not related to lipase enzymatic activity, suggesting that these two factors might be independent. Therefore, although the results indicate a dietary effect on lipase specific activity, probably caused by differences in the FA composition of the diet, the physiological consequences of such a regulation remains unclear. A large excess of pancreatic lipase secretion in relation to dietary needs has been reported in humans (Brannon, 1990) and, if this is also the case in young fish, a diminished lipase specific activity might not necessarily affect growth. In larval red drum fed a microparticulate diet, live prey or both, enzyme activity was not the limiting factor for growth (Lazo et al., 2000). A high enzymesubstrate ratio has also been measured for proteolytic enzymes in larval herring (Pedersen, 1984; Pedersen et al., 1987). Finally, measurements of BSDL in turbot larvae suggest that it is present in surplus for the digestion of all ingested prey (Hoehne-Reitan et al., 2001a).

\section{Effect of dietary lipid level on nutrient absorption}

In spite of the considerable progress achieved in the last few years in the development of inert diets, feeding marine fish larvae on live preys still leads to better growth and survival results. Therefore, the intensive larval rearing of the majority of marine fish species continues to be based on the provision of live food during the early larval stages (Cahu and Zambonino Infante, 2001). However, both rotifers and Artemia, the most commonly used preys in larviculture, have a deficient nutritional composition, particularly in terms of EFA. To overcome their nutritional deficiency, enrichment products and protocols have been developed over the last decades to enrich these zooplankton with sufficient levels of EFA (Rodríguez et al., 1996; Rainuzzo et al., 1994, 1997; Han et al., 2000). In order to meet the EFA requirements of the larvae and thus achieve good growth, survival and larval quality, the general approach is to simulate the biochemical composition of the larva's natural diet (marine plankton), which is particularly rich in (n-3) PUFA. However, the natural marine phytoplankton and zooplankton is composed mostly of (n-3) PUFA-rich phospholipids $(P L)$, while many of the enrichment methodologies use lipid sources rich in TAG, which have a lower ( $n-3)$ PUFA content compared to polar lipids (Sargent et al., 1989). Therefore, in order to supply high levels of EFA, live prey fed to larvae may have an excessive total lipid content having a high neutral lipid composition. In fact, a few studies have reported poor larval growth on high dietary lipid, where the authors hypothesized that quantitative and qualitative imbalances in the macronutrient composition of the diet, particularly neutral lipid excess, may lead to a lower larval digestion and absorption ability (Kjørvik et al., 1991a; Hoehne, 1999; Pousão-Ferreira et al., 1999; Izquierdo et al., 2000; Olsen et al., 2000a), resulting in poor growth and larval performance. Additionally, Gara et al. (1998) suggests that the overall level of lipid intake may also have a significant influence on flatfish metamorphosis success.

On the other hand, larvae fed TAG rich diets commonly show an accumulation of lipid vacuoles in the basal zone of the enterocytes, which indicates a good digestion and absorption of dietary TAG but a reduced transport capacity (Díaz et al., 1997; Fontagné et al., 1998; Salhi et al., 1999; Izquierdo et al., 2000). Loewe and Eckman (1988) reported a lipid accumulation in the epithelium of the intestine of the coregonid, Coregonus fera, larvae, which was particularly intense between 7 and 13 days after start feeding but diminished after two weeks of feeding. The authors claimed that this was due to a lower basal transport rate across the membrane of the enterocyte during the earlier period of larval development, becoming more efficient later. It was suggested that even if the morphological appearance of the intestinal cells remains unchanged, the "biochemical machinery" or the intracellular compartments responsible for the assembly of lipoproteins might be less developed in the early larval stages (Loewe and Eckman, 1988). Nevertheless, similar lipid accumulations have been reported in adults of many fish species and they are probably a natural occurrence resulting from slow lipid processing, where there is a temporal separation between FA assimilation and secretion by the intestinal tissue (Noaillac-Depeyre and Gas, 1974; Sire and Vernier, 1981). Once absorbed by the enterocyte, the products of lipid digestion migrate from the site of absorption to the ER, where complex lipids are resynthesized and deposited in lipid droplets in mucosal epithelial cells (Tso and Fujimoto, 1991; Nordskog et al., 2001). However, in fish there are differences between the rate of luminal lipid digestion and diffusion of FA into the gut epithelia, which are not affected by water 
temperature, and the rate of reacylation into TAG and lipoprotein synthesis, which are slowed down by low water temperatures (Austreng et al., 1979; Sire and Vernier, 1981). Noaillac-Depeyre and Gas (1974) observed two types of lipid inclusions in the enterocytes of the carp: lipid particles or lipoproteins $(<100 \mathrm{~nm}$ in diameter), which were implicated in the direct transport of absorbed FA into the blood circulation, and lipid droplets (that may reach several microns in diameter), which seem to act as temporary sites of lipid storage. Unbalanced diets may lead to greater lipid accumulation by enhancing the discrepancy between the rates of absorption and lipoprotein synthesis.

In terms of dietary lipid imbalances, the effect of PL deficiency has been quite extensively studied (see Coutteau et al., 1997 for a more complete review). A beneficial effect of dietary PL supplementation has been observed on the larval growth and survival of several fish species (Kanazawa et al., 1983; Kanazawa, 1993). One observed effect of dietary PL supplementation in gilthead seabream has been an increase in diet ingestion rate up to $30 \mathrm{DAH}$, suggesting that phosphatidylcholine (PC) may act as an age-dependent attractant (Koven et al., 1998; Hadas et al., 2003). A role of PL in enhancing lipid emulsification, in the absence of sufficient levels of larval bile salts, had also been suggested by Koven et al. (1993) but could not be substantiated in subsequent studies (e.g., Hadas et al., 2003). The more important effect of dietary PL appears to be related to its role in lipid transport from the enterocyte to the tissues (Hadas et al., 2003; Geurden et al., 1995; Fontagné et al., 1998; Olsen et al., 1999; Salhi et al., 1999). Numerous studies have shown that larval diets deficient in PL lead to the accumulation of large amounts of lipid vacuoles in the enterocytes, probably due to insufficient lipoprotein synthesis (Díaz et al., 1997; Fontagné et al., 1998; Olsen et al., 1999; Salhi et al., 1999; Izquierdo et al., 2000). Lipoprotein production by the enterocyte involves a complex sequence of biosynthetic events that bring together specific apoproteins, PL (mostly PC), cholesterol, cholesterol ester, carbohydrate and reesterified TAG (Vernier and Sire, 1986). Iritani et al. (1984) reported that the $\alpha$-glycerophosphate acyltransferase activity of fish is extremely low compared to other animals and it is now well established that marine fish, particularly in the larval stages, have a limited capacity for endogenous "de novo" PL biosynthesis, which may be insufficient to maintain an optimal rate of lipoprotein synthesis. Therefore, a specific dietary requirement for dietary polar lipid for the transport of lipids through the intestinal membranes (by enhancing lipoprotein synthesis) has been suggested (Fontagné et al., 1998; Olsen et al., 1999; Salhi et al., 1999; Hadas et al., 2003).

In recent studies by Morais et al. (2005b,c), two experiments were conducted with Senegalese sole (Solea senegalenis Kaup 1858) larvae, where feeding on higher neutral lipid Artemia (enriched on soybean oil emulsion; EA) induced an enhanced accumulation of lipid droplets in the larval enterocytes and resulted in lower growth, compared to larvae fed low lipid Artemia (non enriched; NEA). This enabled the extent that lipid vacuoles in the enterocytes may influence the capacity of sole larvae to digest and absorb FA (Morais et al., 2005b), as well as proteins and AA, to be studied (Morais et al., 2005c).

\subsection{Fatty acid absorption}

When Senegalese sole larvae that were fed either EA or NEA from 16 to 32 DAH were tube fed lipid mixtures containing ${ }^{14} \mathrm{C}-\mathrm{OA}$, either in the free form or esterified to a TAG (glycerol tri[1- $\left.{ }^{14} \mathrm{C}\right]$ oleate; TRI) or to a PL (L-3-phosphatidylcholine 1,2, di-[1- $\left.{ }^{14} \mathrm{C}\right]$ oleoyl; PC), a significant effect of the Artemia diet (two-way ANOVA, $p=0.001$ ) was noted on the absorption of the labels (Fig. 4). This effect was particularly marked when TRI was tube fed, being a non significant trend (if a one-way ANOVA is conducted) for the free OA and PC labels. The larvae which had been fed EA showed a significantly increased evacuation of the labelled FA, suggesting that the long term feeding of a diet higher in neutral lipid may affect the capacity of larvae to efficiently absorb dietary FA (Morais et al., 2005b). In addition, independently of the previous feeding regime, the TRI label was considerably more evacuated into the incubation water than labeled PC, indicating that sole larvae have a lower capacity to digest and absorb a TAG compared to PL. This might be due to a more deficient emulsification and lower efficiency of neutral lipases, compared to phospholipases.

Therefore, it appears that the accumulation of lipid droplets within the gastrointestinal mucosa may present a physical barrier to efficient lipid absorption, which in turn may explain the lower growth observed in larvae fed the higher neutral lipid diet. Initially, in studies performed with rats, it was thought that the rate limiting step for the esterification in the intestinal mucosa was the FA absorption from the lumen but it was later discovered that an increase in the esterification rate resulted in an increased OA flux from the lumen (Borgström, 1977). Therefore, the intracellular FA pool may regulate the uptake into the enterocytes. This may also explain why, in fish larvae, a higher accumulation of lipid in the enterocytes might lead to an impaired FA absorption and increased evacuation. However, 
the results presented in Morais et al. (2005b) (also discussed in Conceição et al., in this issue), suggest that this effect depends also on the FA nature, as different FA may show a specific pattern of digestion, absorption and utilization. In particular, docosahexaenoic acid (DHA) was seen to be almost completely absorbed and mostly retained in the tissues, independently of the previous feeding regime. Therefore, it may be that, as a result of the high specificity of digestive enzymes towards (n-3) PUFA (Austreng et al., 1979; Lie et al., 1987; Koven et al., 1994b; Olsen et al., 1998) and of the presumed higher affinity of cytosolic FA-binding proteins and higher rate of esterification of long-chain PUFA (Sire and Vernier, 1981; Poirier et al., 1997; Pérez et al., 1999), the accumulation of lipid droplets in the enterocytes may not be an obstacle for the efficient dietary utilization of EFA. This being the case, effects on growth would then be explained by a lower absorption of SFA and MUFA which are normally directed into energy-producing catabolic pathways, eventually sparing protein for growth.

Morais et al. (2005b) tested two Artemia diets which differed not only in their total lipid content but also in their relative FA profile, although both were deficient in EFA. Nevertheless, in carnivorous juvenile and adult fish, the inclusion of plant-derived oils may result in a reduction of the transport rate across the gut epithelia and thus in the accumulation of lipid droplets in the enterocytes, possibly leading to tissue damage and compromised gut integrity (Olsen et al., 1999, 2000b, 2003; Caballero et al., 2002, 2003). Indeed, it has been hypothesized that the dietary FA composition may influence not only the composition, morphology and fluidity of the intestinal cells but also the physiological mechanisms involved in intestinal lipid metabolism and transport (Sire and Vernier, 1981; Caballero et al., 2002, 2003). One of the suggested potential metabolic effects would be in the intracellular pathways of TAG and PL reacylation, which appear to be affected by the nature of dietary lipids (Sire and Vernier, 1981; Pérez et al., 1999; Izquierdo et al., 2000; Olsen et al., 2000b), although Oxley et al. (2005) did not find a significant effect of the replacement of fish oil by vegetable oil in the diet of Atlantic salmon on the activity of enzymes involved in the intestinal reacylation of digested lipid into TAG or PL. Therefore, a follow up study was conducted with Senegalese sole using Artemia diets enriched with higher and lower levels of the same lipid emulsion (i.e., with an equivalent FA profile) and comparing two different lipid sources - fish oil and soybean oil (Morais et al., 2006a). Differences in lipid accumulation within the gut enterocytes were induced by the experimental diets, with a higher amount of lipid droplets being noticeable in the midgut epithelia of larvae fed Artemia enriched with higher fish oil (HF) and soybean oil (HS) doses, compared to the lower lipid treatments (LF and LS). The observed differences appeared to be directly correlated to the dietary quantitative supply of neutral lipid and an effect of dietary lipid source was not clearly noticeable. In addition, the results also confirmed earlier suggestions linking an increase in the total neutral lipid content of the diet and the accumulation of lipid droplets within the gut enterocytes with a decrease in the absorption efficiency of tube fed TRI. It remains however to be established to what extent the FA composition of the dietary lipid may exert an influence over this process. The experimental approach that was followed, namely the use live preys enriched with different doses of lipid emulsion, did not enable achieving important differences in total lipid level between the higher and lower lipid diets. As in many other areas of fish larval nutrition, the development of inert diets enabling a better control of the dietary composition is highly desirable and needed, in order to proceed with the investigation of the effects of total lipid level and lipid source on larval performance and digestive physiology.

\subsection{Amino acid absorption}

The mechanisms associated with lipid and protein absorption are fundamentally different. Nonetheless, considering that growth is mainly the result of protein deposition, a study was conducted with Senegalese sole larvae using the feeding regimes previously tested, with the objective of examining whether a higher neutral lipid regime inducing the accumulation of lipid droplets in the gut epithelium may also affect AA absorption and metabolism (Morais et al., 2005c). Few studies have examined this interaction and the existing results are contradictory. Kjørsvik et al. (1991a) reported alterations in protein absorption in the hindgut of turbot larvae fed rotifers with a high lipid content while Olsen et al. (1999), when describing pinocytotic activity related to protein hydrolysis in Arctic charr, noted that it was not affected by diets inducing differences in accumulation of lipid droplets in the enterocytes. Senegalese sole larvae that were fed either NEA or EA from 16 DAH onwards were allowed to feed on Artemia radiolabelled with a $\left[\mathrm{U}-{ }^{14} \mathrm{C}\right]$ protein hydrolysate, in which most of the label is incorporated into the protein fraction (Morais et al., 2004b). Both dietary treatments had a very similar high absorption of the AA label after a $24 \mathrm{~h}$ incubation period (75-76\%; Fig. 5), which suggests that the intracellular lipid inclusions in the enterocytes do not affect AA absorption, in accordance with the observations made by Olsen et al. (1999). Nevertheless, the significantly higher amount of label 
found in the incubation water of larvae from the NEA treatment, $3 \mathrm{~h}$ after feeding (Fig. 5), appears to indicate a faster evacuation and thus a more rapid processing of the Artemia meal by these larvae. AA label catabolism was also significantly higher at 3 and $24 \mathrm{~h}$ in the NEA treatment, which might be explained by the faster AA absorption resulting in more time for its metabolic use. Therefore, in a continuous feeding situation, a higher net AA absorption may be achieved in larvae fed NEA through a more rapid clearance of the lumen leading to sustained appetite and ingestion of the diet (Morais et al., 2005c). The higher growth of larvae fed NEA may thus be explained by a higher FA absorption efficiency and/or by an increased ingestion rate of a diet containing a lower lipid level (i.e. a lower energy diet).

\section{Effect of dietary lipid on food intake}

The most commonly proposed explanation for the lower larval growth which is sometimes obtained with high lipid diets has been related to an overload of the digestive and absorptive capacity caused by excess lipid, as discussed above. However, another alternative or additional possibility is that the higher dietary lipid level, resulting in more energy-dense diets, may induce a lower food intake and consequently an insufficient intake of protein and essential nutrients (e.g. HUFA) and micronutrients. This possibility has been previously suggested (Pousão-Ferreira et al., 1999; Gawlicka et al., 2002; Morais et al., 2005c) but has not been directly tested in marine fish larvae. In spite of the lack of studies at the larval stage, the effect of dietary total lipid level on food intake has been one of the most frequently addressed questions in juvenile and adult fish nutrition studies. Although a few exceptions have been found (e.g., Alanärä, 1994), the majority of the work performed on several juvenile and adult fish species established a regulation of food intake by dietary digestible energy content, meaning that fish ingest different amounts of food to meet a certain set energy requirement, except when the diet has such a low energy density that stomach volume becomes limiting or if very high energydensity diets are ingested in larger amounts to avoid an under filled stomach (Lee and Putnam, 1973; Marais and Kissil, 1979; Boujard and Médale, 1994; Santinha et al., 1999; Ogata and Shearer, 2000; Yamamoto et al., 2000; Sæther and Jobling, 2001; Gélineau et al., 2001, 2002; Boujard et al., 2004; Skalli et al., 2004). A lower ingestion of high lipid (i.e. high energy) diets results therefore in a lower intake of protein but most authors reported a growth similar to that obtained with a lower lipid diet, as a result of a protein-sparing effect. In fish larvae nothing has been documented concerning the eventual existence of a protein-sparing effect. Results from the adult can not be extrapolated given that fish larvae have much higher requirements for energy and structural components, while dietary lipid (particularly EFA) is also extremely important for early organ development and for physiologically demanding processes such as metamorphosis. These differences in requirements, coupled with changes in the structure of the gastrointestinal tract, as discussed above, are likely to result in a dissimilar metabolism. Given the potential impact of food intake in larval growth, studies in this area are essential, as they are likely to contribute to massive rises in the productivity of marine hatcheries.

These questions have recently been addressed in a marine fish larva. Morais et al. (2006b) carried out a study on the regulation of food intake and nutrient absorption in seabream (Sparus aurata L.) larvae by dietary lipid level and FA composition. In one experiment, larval performance was tested when the fish were fed Artemia enriched on one of two levels of a fish oil emulsion, while in a second experiment larvae were co-fed Artemia enriched on one of two levels of soybean oil emulsion together with a microdiet (MD) containing soybean oil, at a corresponding lipid level. After a period of feeding on the experimental diets, trials were conducted using ${ }^{14} \mathrm{C}$-markers in order to quantify food ingestion and absorption. When seabream larvae were fed diets containing higher and lower amounts of soybean oil (HS and LS) they fed significantly more on the LS diet (Fig. 6B). Therefore, in this case, the total lipid level of the diet was inversely correlated with food intake, as observed in older fish. However, when higher and lower lipid Artemia were enriched with fish oil instead (HF and LF), the opposite was noted, i.e., larvae on the HF diet demonstrated a significantly higher food intake (Fig. $6 \mathrm{~A})$. Therefore, these results indicate that in seabream larvae food intake may not be simply regulated by total lipid level in the diet and that dietary FA composition possibly has a more important role in controlling ingestion. In addition, food intake did not appear to have been regulated to meet a requirement for EFA, as HF and LS presented higher or similar levels of EFA than their counterpart treatment.

It is reasonable to suggest that the biochemical composition of the food, by influencing the digestive and absorptive processes, can indirectly affect the rate of gut clearance and, consequently, the feeding rates. In fact, food intake and absorption efficiency are commonly interrelated (Werner and 
Blaxter, 1980; Ryer and Boehlert, 1983; Boehlert and Yoklavich, 1984). Hadas et al. (2003) showed that when seabream larvae were fed a PC-supplemented $M D$, an enhanced ${ }^{14} \mathrm{C}$-OA transport from the gut enterocytes into the larval body occurred, along with an increased diet ingestion. Therefore, FA digestibility, which depends on chain length and degree of saturation (Austreng et al., 1979; Olsen et al., 1998; Johnsen et al., 2000; Caballero et al., 2002; Morais et al., 2005b), may have an indirect effect on food intake. SFA are less digestible and high levels of these FA in the diet might reduce the apparent digestibility of other FA and thus the total digestible energy content of the diet (Austreng et al., 1979; Caballero et al., 2002). Given the high digestibility of long chain (n-3) PUFA, Artemia enriched with fish oil may be more digestible for marine fish larvae than with soybean oil. If the HF Artemia is digested and absorbed faster than the LF diet, the gut of the larvae feeding on this diet may be cleared sooner, thus leading to sustained feeding and appetite and indirectly leading to a higher food intake. On the other hand, Artemia enriched on higher levels of soybean oil (HS) may have detrimental effects on lipid digestion and absorption, which might delay gastric emptying and thus result in a lower ingestion rate. However, the absorption efficiency of the radioactive labels was analyzed and does not support this hypothesis, given that the LF diet was more absorbed from the gut into the body tissues than the HF Artemia, while the soybean oil diets appear to have been both equally efficiently absorbed (Fig. 6). The fish oil treatments results confirm that a higher food intake may decrease nutrient absorption efficiency, possibly as a result of more rapid passage through the gut (Werner and Blaxter, 1980; Ryer and Boehlert, 1983; Boehlert and Yoklavich, 1984; Hoehne et al., 2001b), while in the soybean oil experiment total absorption appeared to be correlated with food intake.

In the soybean oil experiment the same trend was noted in terms of food intake and absorption when the MD ${ }^{14} \mathrm{C}$-label was TRI or OA, which indicates that the differences observed between the HS and LS diets were not due to differences in the capacity to digest the diets but were more a question of FA absorption. Nevertheless, contrary to what was observed with Senegalese sole, the histological analysis of the gastrointestinal tract did not reveal any obvious difference in lipid accumulation between seabream larvae fed the higher and lower lipid diets, independently of the lipid source. This may be due to species-specific differences or to the fact that in these experiments there was a higher dietary supply of PL, included in the MD, or added to the Artemia in the form of liposomes.

Another parameter which may potentially exert some effect on food intake and that has not been investigated in fish larvae is palatability. When feeding Artemia, even if a direct orosensory or taste effect of the oils is unlikely, as they are absorbed and converted into the Artemia's body nutrients, Artemia washing after enrichment might be insufficient to remove all residues of the lipid emulsions from the exoskeleton. In the case of formulated MD, taste may have a more important effect. In addition, the possibility exists that the dietary FA composition may exert an influence at the hormonal level, such as through effects on the release of CCK, which is involved in the control of gastric emptying (Holmgren, 1993; Olsson et al., 1999) and food intake (Himick and Peter, 1994; Gélineau and Boujard, 2001), and whose secretion can be affected by the chemical nature of the FA, as discussed above.

\section{Conclusions and future perspectives}

One of the central objectives in marine larviculture has been, for at least the last two decades, the replacement of live trophic chains by inert formulated diets, which has significant implications for the future economic viability of aquaculture. However, in order to achieve this, a detailed understanding of the larval digestive physiology and how it is modulated by the diet is essential. The current perception, based on the few results obtained so far by studying lipid digestion and transport in fish larvae, is that the transport of lipid from the enterocytes into the body may be more of a problem in small larvae than lipid digestion, although both factors may intervene (Izquierdo et al., 2000; Morais et al., 2005a,b). Atlantic herring larvae were able to deal quite effectively with a pure lipid diet, showing considerable mechanical and chemical action that was effective in emulsifying the lipid in the absence of exogenous dietary emulsifiers (Morais et al., 2005a). In tracer experiments conducted with different species (Atlantic herring, Senegalese sole and seabream), feeding on free OA always resulted in a more efficient absorption than TRI, indicating that neutral lipases were not entirely efficient (Morais et al., $2005 a, b, 2006 a, b)$. On the other hand, the results obtained with Senegalese sole larvae appear to suggest that PL digestion may be more efficient, possibly as a result of a higher activity of phospholipases, compared to neutral lipases (Morais et al., 2005b). Nonetheless, in seabass, even though dietary FA composition significantly affected lipase activity, no correlation was found between 
enhanced lipolytic activity and growth (Morais et al., 2004a). It has been suggested that digestive enzymes are produced in excess to standard dietary needs and this might be particularly relevant in larvae with relatively short guts, where a high digestive activity may compensate for the fast gut transit time. Therefore, existing data seems to collectively indicate that the enzymatic capacity is not a limiting factor for fish larvae to deal with high lipid diets.

The main obstacle to high lipid inclusion levels in diets for marine fish larvae may thus be at the absorption level. Feeding larvae on high neutral lipid diets, particularly when PL supply is deficient, results in the accumulation of lipid droplets in the enterocytes, which may in turn reduce the absorption of the FA products of luminal digestion (Morais et al., 2005b). Even so, not all FA are equally affected by the lipid accumulation in the enterocytes and mechanisms of specific PUFA absorption and preferential incorporation into structural tissues probably exist to minimize EFA deficiency. Nevertheless, lipids are also an important source of metabolic energy and the supply of SFA and MUFA in sufficient amounts is critical, particularly in fast growing larvae with high developmental energetic demands. Very little is known regarding the cytological and biochemical aspects of lipid absorption in fish and virtually no studies exist for fish larvae. The events occurring between luminal lipolysis and assembly of lipid digestion products into the lipoproteins that will transport the lipid into the body tissues are still a mystery.

Seabream larvae do not regulate their food intake simply according to total lipid level (Morais et al., 2006b). A stringent control of food intake by dietary energy level or a lipostatic regulation of food intake may not be so likely in fish larvae which have a much higher demand for energy and structural components required for growth, early organ development and physiologically demanding processes, such as metamorphosis. Morais et al. (2006b) have also shown that dietary FA composition seems to play a major role on nutrient absorption and ingestion but the exact mechanisms behind these observations still need to be clarified.

Therefore, lipid level in diets for marine fish larvae may have an important impact in several factors influencing growth and development but clearly it cannot be dissociated of its FA composition, which appears to play a central role on the nutritional and physiological impacts of dietary lipid inclusion, at the ingestion, digestion and absorption levels. It is hoped that future studies based on molecular approaches will allow more insight into the physiological mechanisms occurring inside the larval enterocyte and their regulation by the diet. In addition, knowledge in this field is expected to advance greatly in the near future with the improvement of formulated diets, which will boost nutritional studies and lead to considerable progress which can then be directly re-invested in the development of increasingly better formulations. In particular, even though quite a lot has been done to study EFA requirements, more attention needs to be given to the balance between EFA and other FA which are a source of metabolic fuel, to determine suitable ratios of neutral to polar lipid enabling an optimized utilization (absorption and retention) of the dietary total lipid fraction, as well as to the global macronutrient composition of the diet, namely the balance between protein and lipid relative levels, to verify whether a protein-sparing effect may be achieved in marine fish larvae.

\section{Acknowledgements}

Sofia Morais is the holder of a PhD grant from the "Fundação para a Ciência e a Tecnologia", Portugal (SFRH/BD/4902/2001). In addition, the work presented here benefited from funding by Project DIVERAQUA/SP5.E36 (programme INTERREG III A, Co-funded by FEDER, European Commission) and from the European Commission (ASEFAF, EEC HPRI - CT - 2001 - 0014 ; IFREMER ref. No. 01/1214121/TF). The authors would like to express their gratitude to several people for their multiple technical and scientific support: Helena Teixeira and Helena Damásio (CCMAR, University of Algarve), Carlos Rojas-Garcia (University of Bergen, Norway), Jean Robin, Patrick Quazuguel, Magali Hervy, Marie Le Gall and Hervé Le Delliou (IFREMER-Brest, France), Oryia Nixon, Michal Torten and Sigal Lutzky (IOLR, Eilat, Israel), Maria José Caballero and Marisol Izquierdo (ULPGC/ICCM, Las Palmas de Gran Canaria, Spain). 


\section{References}

Alanärä, A., 1994. The effect of temperature, dietary energy content and reward level on the demand feeding activity of rainbow trout (Oncorhynchus mykiss). Aquaculture 126, 349-359.

Aldman, G., Holmgren, S., 1995. Intraduodenal fat and amino acids activate gallbladder motility in the rainbow trout, Oncorhynchus mykiss. Gen. Comp. Endocr. 100, 27-32.

Aldman, G., Grove, D., Holmgren, S., 1992. Duodenal acidification and intra-arterial injection of CCK-8 increase gallbladder motility in the rainbow trout, Oncorhynchus mykiss. Gen. Comp. Endocr. 86, 20-25.

Austreng, E., Skrede, A., Eldegard, A., 1979. Effect of dietary fat source on the digestibility of fat and fatty acids in rainbow trout and mink. Acta Agric. Scand. 29, 119-126.

Bach, A.C., Babayan, V.K., 1982. Medium-chain triglycerides: an update. Am. J. Clin. Nutr. 36, 950962.

Boehlert, G.W., Yoklavich, M.M., 1984. Carbon assimilation as a function of ingestion rate in larval pacific herring, Clupea harengus pallasi Valenciennes. J. Exp. Mar. Biol. Ecol. 79, 251-262.

Borgström, B., 1977. Digestion and absorption of lipids. In: Crane, R.K. (Ed.), International Review of Physiology, Gastrointestinal Physiology II, Volume 12. University Park Press, Baltimore, USA, pp. 305-323.

Borlongan, I.G., 1990. Studies on the digestive lipases of milkfish, Chanos chanos. Aquaculture 89, 315-325.

Boujard, T., Médale F., 1994. Regulation of voluntary feed intake in juvenile rainbow trout fed by hand or by self feeders with diets containing two different protein/energy ratios. Aquat. Living Resour. 7 , 211-215.

Boujard, T., Gélineau, A., Covès, D., Corraze, G., Dutto, G., Gasset, E., Kaushik, S., 2004. Regulation of feed intake, growth, nutrient and energy utilization in European sea bass (Dicentrarchus labrax) fed high fat diets. Aquaculture 231, 529-545.

Boulhic, M., Gabaudan, J., 1992. Histological study of the organogenesis of the digestive system and swim bladder of the Dover sole, Solea solea (Linnaeus 1758). Aquaculture 102, 373-396.

Brannon, P.M., 1990. Adaptation of the exocrine pancreas to diet. Ann. Rev. Nutr. 10, 85-105.

Buchet, V., Zambonino Infante, J.L., Cahu, C.L., 2000. Effect of lipid level in a compound diet on the development of red drum (Sciaenops ocellatus) larvae. Aquaculture 184, 339-347.

Caballero, M.J., Obach, A., Rosenlund, G., Montero, D., Gisvold, M., Izquierdo, M.S., 2002. Impact of different dietary lipid sources on growth, lipid digestibility, tissue fatty acid composition and histology of rainbow trout, Oncorhynchus mykiss. Aquaculture 214, 253-271.

Caballero, M.J., Izquierdo, M.S., Kjørsvik, E., Montero, D., Socorro, J., Fernández, A.J., Rosenlund, G., 2003. Morphological aspects of intestinal cells from gilthead seabream (Sparus aurata) fed diets containing different lipid sources. Aquaculture 225, 325-340.

Cahu, C., Zambonino Infante, J., 2001. Substitution of live food by formulated diets in marine fish larvae. Aquaculture 200, 161-180.

Cahu, C.L., Zambonino Infante, J.L., Le Gall, M.M., Quazuguel, P., 1995. Early weaning of seabass: are digestive enzymes limiting? In: Lavens, P., Jaspers, E., Roelants, I. (Eds.), LARVI '95 - Fish \& Shellfish Larviculture Symposium. European Aquaculture Society, Special Publication No. 24, Gent, Belgium, pp. 268-271.

Cahu, C., Rønnestad, I., Grangier, V., Zambonino-Infante, J.L., 2004. Expression and activities of pancreatic enzymes in developing sea bass larvae (Dicentrarchus labrax) in relation to intact and hydrolyzed dietary protein; involvement of cholecystokinin. Aquaculture 238, 295-308.

Cousin, J.C.B., Baudin-Laurencin, F., Gabaudan, J., 1987. Ontogeny of enzymatic activities in fed and fasting turbot, Scophthalmus maximus L.. J. Fish Biol. 30, 15-33.

Coutteau, P., Geurden, I., Camara, M.R., Bergot, P., Sorgeloos, P., 1997. Review on the dietary effects of phospholipids in fish and crustacean larviculture. Aquaculture 155, 149-164.

Deplano, M., Diaz, J.P., Connes, R., Kentouri-Divanach, M., Cavalier, F., 1991. Appearance of lipidabsorption capacities in larvae of the sea bass Dicentrarchus labrax during transition to the exotrophic phase. Mar. Biol. 108, 361-371.

Diaz, J.P., Guyot, E., Vigier, S., Connes, R., 1997. First events in lipid absorption during postembryonic development of the anterior intestine in gilt-head sea bream. J. Fish Biol. 51, 180-192.

Douglas, B.R., Jansen, J.B.M.J., De Jong, A.J.L., Lamers, C.B.H.W., 1990. Effect of various triglycerides on plasma cholecystokinin levels in rats. J. Nutr. 120, 686-690. 
Einarsson, S., Davies, P.S., Talbot, C., 1997. Effect of exogenous cholecystokinin on the discharge of the gallbladder and the secretion of trypsin and chymotrypsin from the pancreas of the Atlantic salmon, Salmo salar L. Comp. Biochem. Physiol. 117C, 63-67.

Fontagné, S., Geurden, I., Escaffre, A.-M., Bergot, P., 1998. Histological changes induced by dietary phospholipids in intestine and liver of common carp (Cyprinus carpio L.) larvae. Aquaculture 161, 213-223.

Gara, B., Shields, R.J., McEvoy, L., 1998. Feeding strategies to achieve correct metamorphosis of Atlantic halibut, Hippoglossus hippoglossus L., using enriched Artemia. Aquac. Res. 29, 935-948.

García-Hernandez, M.P., Lozano, M.T., Agulleiro, B., 1994. Ontogeny of some endocrine cells of the digestive tract in sea bass (Dicentrarchus labrax): An immunocytochemical study. Cell Tissue Res. 277, 373-383.

Gawlicka, A., Herold, M.A., Barrows, F.T., de la Noüe, J., Hung, S.S.O., 2002. Effects of dietary lipids on growth, fatty acid composition, intestinal absorption and hepatic storage in white sturgeon (Acipenser transmontanus R.) larvae. J. Applied Ichthyol. 18, 673-681.

Gélineau, A., Boujard, T., 2001. Oral administration of cholecystokinin receptor antagonists increase feed intake in rainbow trout. J. Fish Biol. 58, 716-724.

Gélineau, A., Corraze, G., Boujard, T., Larroquet, L., Kaushik, S., 2001. Relation between dietary lipid level and voluntary feed intake, growth, nutrient gain, lipid deposition and hepatic lipogenesis in rainbow trout. Reprod. Nutr. Dev. 41, 487-503.

Gélineau, A., Bolliet, V., Corraze, G., Boujard, T., 2002. The combined effects of feeding time and dietary fat levels on feed intake, growth and body composition in rainbow trout. Aquat. Living Resour. 15, 225-230.

Geurden, I., Radünz-Neto, J., Gergot, P., 1995. Essentiality of dietary phospholipids for carp (Cyprinus carpio L.) larvae. Aquaculture 131, 303-314.

Gjellesvik, D.R., 1991. Fatty acid specificity of bile salt-dependent lipase: enzyme recognition and super-substrate effects. Biochim. Biophys. Acta 1086, 167-172.

Govoni, J.J., Boehlert, G.W., Watanabe, Y., 1986. The physiology of digestion in fish larvae. Environ. Biol. Fish. 16, 59-77.

Hadas, E., Koven, W., Sklan, D., Tandler, A., 2003. The effect of dietary phosphatidylcholine on the assimilation and distribution of ingested free oleic acid (18:1n-9) in gilthead seabream (Sparus aurata) larvae. Aquaculture 217, 577-588.

Han, K., Geurden, I., Sorgeloos, P., 2000. Enrichment strategies for Artemia using emulsions providing different levels of n-3 highly unsaturated fatty acids. Aquaculture 183, 335-347.

Henning, S.J., 1987. Functional development of the gastrointestinal tract. In: Johnson, L.R. (Ed.), Physiology of the Gastrointestinal Tract. Raven Press, NY, pp. 285-300.

Himick, B.A., Peter, R.E., 1994. CCK/gastrin-like immunoreactivity in brain and gut, and CCK suppression of feeding in goldfish. Am. J. Physiol. -Reg. I. 267, R841-R851.

Hoehne, K., 1999. Lipid digestive enzymes in developing larvae of the Atlantic cod (Gadus morhua) and turbot (Scophthalmus maximus). PhD thesis, Universität Karlsruhe.

Hoehne-Reitan, K., Kjørsvik, E., Gjellesvik, D.R., 2001a. Development of bile salt-dependent lipase in larval turbot. J. Fish Biol. 58, 737-745.

Hoehne-Reitan, K., Kjørsvik, E., Reitan, K.I., 2001b. Bile salt-dependent lipase in larval turbot, as influenced by density and lipid content of fed prey. J. Fish Biol. 58, 746-754.

Holmgren, S., 1993. Gut nerves and endocrine cells, and some of their intestinal functions in fish. In: Walther, B.T., Fyhn, H.J. (Eds.), Physiological and biochemical aspects of fish development. University of Bergen, Norway, pp. 209-215.

Honkanen, R.E., Rigler, M.W., Patton, J.S., 1985. Dietary fat assimilation and bile salt absorption in the killifish intestine. Am. J. Physiol. -Gastr. L. 249, G399-G407.

Hopman, W.P.M., Jansen, J.B.M.J., Rosenbusch, G., Lamers, C.B.H.W., 1984. Effect of equimolar amounts of long-chain triglycerides and medium-chain triglycerides on plasma cholecystokinin and gallbladder contraction. Am. J. Clin. Nutr. 39, 356-359.

lijima, N., Aida, S., Mankura, M., Kayama, M., 1990. Intestinal absorption and plasma transport of dietary triglyceride and phosphatidylcholine in the carp (yprinus carpio). Comp. Biochem. Physiol. 96A, 45-55.

lijima, N., Tanaka, S., Ota, Y., 1998. Purification and characterization of bile salt-activated lipase from the hepatopancreas of red sea bream, Pagrus major. Fish Physiol. Biochem. 18, 59-69.

Iritani, N., Ikeda, Y., Fukuda, H., Katsurada, A., 1984. Comparative study of lipogenic enzymes in several vertebrates. Lipids 19, 825-835. 
Izquierdo, M.S., Socorro, J., Arantzamendi, L., Hernández-Cruz, 2000. Recent advances in lipid nutrition in fish larvae. Fish Physiol. Biochem. 22, 97-107.

Johnsen, R.I., Grahl-Nielsen, O., Roem, A., 2000. Relative absorption of fatty acids by Atlantic salmon Salmo salar from different diets, as evaluated by multivariate statistics. Aquacult. Nutr. 6, 255-261.

Kamisaka, Y., Kurokawa, T., Suzuki, T., Tagawa, M., Tanaka, M., Totland, G.K., Rønnestad, I., 2001. Ontogeny of cholecystokinin-immunoreactive cells in the digestive tract of Atlantic halibut (Hippoglossus hippoglossus) larvae. Gen. Comp. Endocr. 123, 31-37.

Kamisaka, Y., Kaji, T., Masuma, S., Tezuka, N., Kurokawa, T., Suzuki, T., Totland, G.K., Rønnestad, I., Tagawa, M., Tanaka, M., 2002a. Ontogeny of cholecystokinin - immunoreactive cells in the digestive tract of bluefin tuna, Thunnus thynnus, larvae. Sarsia 87, 258-262.

Kamisaka, Y., Kurokawa, T., Suzuki, T., Totland, G.K., Rønnestad, I., Tagawa, M. \& Tanaka, M., $2002 \mathrm{~b}$. Ontogenetic appearance and distribution of the digestive hormone cholecystokinin (CCK) in fish. Fish. Sci. 68, Supplement I, 963- 964.

Kamisaka, Y., Fujii, Y., Yamamoto, S., Kurokawa, T., Rønnestad, I., Totland, G.K., Tagawa, M., Tanaka, M., 2003. Distribution of cholecystokinin - immunoreactive cells in the digestive tract of the larvae teleost ayu, Plecoglossus altivelis. Gen. Comp. Endocr. 134, 116-121.

Kanazawa, A., 1993. Essential phospholipids of fish and crustaceans. In: Kaushik, S.J., Luquet, P. (Eds.), Fish Nutrition in Practice. IV International Symposium on Fish Nutrition and Feeding, INRA, France, pp. 519-530.

Kanazawa, A., Teshima, S., Inamori, S., Matsubara, H., 1983. Effects of dietary phospholipids on growth of the larval red sea bream and knife jaw. Mem. Fac. Fish., Kagoshima Univ. 32, 109-114.

Kjørsvik, E., Olsen, Y., Rosenlund, G., Vadstein, O., 1991. Effect of various lipid enrichments in rotifers and the development of early stages in turbot. In: Lavens, P., Sorgeloos, P., Jaspers, E., Ollevier, F. (Eds.), Larvi '91 - Fish and Crustacean Larviculture Symposium. European Aquaculture Society, Special Publication, Vol. 15, Gent, Belgium, pp. 20-22.

Kjørsvik, E., Van der Meeren, T., Kryvi, H., Arnfinnson, J., Kvenseth, P.G., 1991b. Early development of the digestive tract of cod larvae, Gadus morhua L., during start-feeding and starvation. J. Fish Biol. 38, 1-15.

Koven, W.M., Kolkovski, S., Tandler, A., Kissil, G.Wm., Sklan, D., 1993. The effect of dietary lecithin and lipase, as a function of age, on n-9 fatty acid incorporation in the tissue lipids of Sparus aurata larvae. Fish Physiol. Biochem. 10, 357-364.

Koven, W.M., Henderson, R.J., Sargent, J.R., 1994a. Lipid digestion in turbot (Scophthalmus maximus) II: Lipolysis in vitro of ${ }^{14}$ C-labelled triacylglycerol, cholesterol ester and phosphatidylcholine by digesta from different segments of the digestive tract. Fish Physiol. Biochem. 13, 275-283.

Koven, W.M., Henderson, R.J., Sargent, J.R., 1994b. Lipid Digestion in Turbot (Scophthalmus maximus). I: Lipid Class and Fatty Acid Composition of Digesta from Different Segments of the Digestive Tract. Fish Physiol. Biochem. 13, 69-79.

Koven, W.M., Parra, G., Kolkovski, S., Tandler, A., 1998. The effect of dietary phosphatidylcholine and its constituent fatty acids on microdiet ingestion and fatty acid absorption rate in gilthead seabream, Sparus auratus, larvae. Aquacult. Nutr. 4, 39-45.

Koven, W., Rojas-Garcia, C.R., Finn, R.N., Tandler, A., Rønnestad, I., 2002. Stimulatory effect of ingested protein and/or free amino acids on the secretion of the gastro-endocrine hormone cholecystokinin and on tryptic activity, in early-feeding herring larvae, Clupea harengus. Mar. Biol. 140, $1241-1247$.

Kurokawa, T., Suzuki, T., 1996. Formation of the diffuse pancreas and the development of digestive enzyme synthesis in larvae of the Japanese flounder Paralichthys olivaceus. Aquaculture 141, 267276.

Kurokawa, T., Suzuki, T., Andoh, T., 2000. Development of cholecystokinin and pancreatic polypeptide endocrine systems during the larval stage of Japanese flounder, Paralichthys olivaceus. Gen. Comp. Endocr. 120, 8-16.

Kurokawa, T., linuma, N., Unuma, T., Tanaka, H., Kagawa, H., Ohta, H., Suzuki, T., 2004. Development of endocrine system regulating exocrine pancreas and estimation of feeding and digestive ability in Japanese eel larvae. Aquaculture 234, 513-525.

Lauff, M., Hofer, R., 1984. Proteolytic enzymes in fish development and the importance of dietary enzymes. Aquaculture 37, 335-346.

Lazo, J.P., Holt, G.J., Arnold, C.R., 2000. Ontogeny of pancreatic enzymes in larval red drum Sciaenops ocellatus. Aquacult. Nutr. 6, 183-192. 
Lee D.J., Putnam G.B., 1973. The response of rainbow trout to varying protein/energy ratios in a test diet. J. Nutr. 103, 916-922.

Lie, Ø., Lambertsen, G., 1985. Digestive lipolytic enzymes in cod (Gadus morhua): fatty acid specificity. Comp. Biochem. Physiol. 80B, 447-450.

Lie, Ø., Lied, E., Lambertsen, G., 1987. Lipid digestion in cod (Gadus morhua). Comp. Biochem. Physiol. 88B, 697-700.

Linscheer, W.G., Vergroesen, A.J., 1994. Lipids. In: Shils, M.E., Olson, J.A., Shike, M. (Eds.), Modern Nutrition in Health and Disease. Williams \& Wilkins, USA, pp. 47-88.

Loewe, H., Eckmann, R., 1988. The ontogeny of the alimentary tract of coregonid larvae: normal development. J. Fish Biol. 33, 841-850.

Marais, J.F.K., Kissil, G.Wm., 1979. The influence of energy level on the feed intake, growth, food conversion and body composition of Sparus aurata. Aquaculture 17, 203-219.

Matzinger, D., Degen, L., Drewe, J., Meuli, J., Duebendorfer, R., Ruckstuhl, N., D’Amato, M., Rovati, L., Beglinger, C., 2000. The role of long chain fatty acids in regulating food intake and cholecystokinin release in humans. Gut 46, 688-693.

Morais, S. , Cahu, C., Zambonino-Infante, J.L. , Robin, J., Rønnestad, I., Dinis, M.T., Conceição, L.E.C., 2004a. Dietary triacylglycerol source and level affects performance and lipase expression in larval seabass (Dicentrarchus labrax). Lipids 39, 449-458.

Morais, S., Conceição, L.E.C., Dinis, M.T., Rønnestad, I., 2004b. A method for radiolabeling Artemia with applications in studies of food intake, digestibility, protein and amino acid metabolism in larval fish. Aquaculture, 231, 469-487.

Morais, S., Rojas-Garcia, C.R., Conceição, L.E.C., Rønnestad, I., 2005a. Digestion and absorption of a pure triacylglycerol and a free fatty acid by Clupea harengus L. larvae. J. Fish Biol. 67, 223-238.

Morais, S., Koven, W., Rønnestad, I., Dinis, M.T., Conceição, L.E.C., 2005b. Dietary protein/lipid ratio and lipid nature affects fatty acid absorption and metabolism in a teleost larva. Br. J. Nutr. 93, 813820.

Morais, S., Koven, W., Rønnestad, I., Dinis, M.T., Conceição, L.E.C., 2005c. Dietary protein/lipid ratio affects growth and amino acid and fatty acid absorption and metabolism in Senegalese sole (Solea senegalensis Kaup 1858) larvae. Aquaculture 246, 347-357.

Morais, S., Caballero, M.J., Conceição, L.E.C., Izquierdo, M.S., Dinis, M.T., 2006a. Dietary neutral lipid level and source in Senegalese sole (Solea senegalensis) larvae: effect on growth, lipid metabolism and digestive capacity. Comp. Biochem. Physiol. 144B, 57-69.

Morais, S., Torten, M., Nixon, O., Lutzky, S., Conceição, L.E.C., Dinis, M.T., Tandler, A., Koven, W., 2006b. Food intake and absorption are affected by dietary lipid level and lipid source in seabream (Sparus aurata L.) larvae. J. Exp. Mar. Biol. Ecol. 331, 51-63.

Noaillac-Depeyre, J., Gas, N., 1974. Fat absorption by the enterocytes of the carp (Cyprinus carpio L.). Cell Tissue Res. 155, 353-365.

Nordrum, S., Krogdahl, Å., Røsjø, C., Olli, J.J., Holm, H., 2000. Effects of methionine, cysteine and medium chain triglycerides on nutrient digestibility, absorption of amino acids along the intestinal tract and nutrient retention in Atlantic salmon (Salmo salar L.) Under Pair-Feeding Regime. Aquaculture 186, 341-360.

Nordskog, B.K., Phan, C.T., Nutting, D.F., Tso, P., 2001. An examination of the factors affecting intestinal lymphatic transport of dietary lipids. Adv. Drug Deliver Rev. 50, 21-44.

Ogata, H.Y., Shearer, K.D., 2000. Influence of dietary fat and adiposity on feed intake of juvenile red sea bream Pagrus major. Aquaculture 189, 237-249.

Olsen A.I., Attramadal Y., Reitan K.I. \& Olsen Y., 2000a. Food selection and digestion characteristics of Atlantic halibut (Hippoglossus hippoglossus) larvae fed cultivated prey organisms. Aquaculture 181, 293-310.

Olsen, R.E., Henderson, R.J., Ringø, E., 1998. The digestion and selective absorption of dietary fatty acids in Arctic Charr, Salvelinus alpinus. Aquacult. Nutr. 4, 13-21.

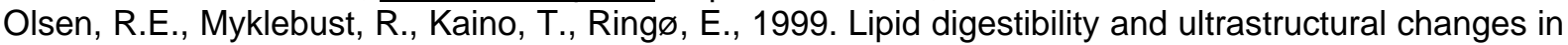
the enterocytes of Arctic char (Salvelinus alpinus L.) fed linseed oil and soybean lecithin. Fish Physiol. Biochem. 21, 35-44.

Olsen, R.E., Myklebust, R., Ringø, E., Mayhew, T.M., 2000b. The influences of dietary linseed oil and saturated fatty acids on caecal enterocytes in Arctic char (Salvelinus alpinus L.): a quantitative ultrastructural study. Fish Physiol. Biochem. 22, 207-216.

Olsen, R.E., Dragnes, B.T., Myklebust, R., Ringø, E., 2003. Effect of soybean oil and soybean lecithin on intestinal lipid composition and lipid droplet accumulation of rainbow trout, Oncorhynchus mykiss Walbaum. Fish Physiol. Biochem. 29, 181-192. 
Olsson, C., Aldman, G., Larsson, A., Holmgren, S., 1999. Cholecystokinin affects gastric emptying and stomach motility in the rainbow trout Oncorhynchus mykiss. J. Exp. Biol. 202, 161-170.

Oxley, A., Torstensen, B.E., Rustan, A.C., Olsen, R.E., 2005. Enzyme activities of intestinal triacylglycerol and phosphatidylcholine biosynthesis in Atlantic salmon (Salmo salar L.). Comp. Biochem. Physiol. 141B, 77-87.

Pedersen, B.H., 1984. The intestinal evacuation rates of larval herring (Clupea harengus L.) predating on wild plankton. Dana 3, 21-30.

Pedersen, B.H., Nilssen, E.M., Hjelmeland, K., 1987. Variations in the content of trypsin and trypsinogen in larval herring (Clupea harengus) digesting copepod nauplii. Mar. Biol. 94, 171-181.

Pérez, J.A., Rodríguez, C., Henderson, R.J., 1999. The uptake and esterification of radiolabelled fatty acids by enterocytes isolated from rainbow trout (Oncorhynchus mykiss). Fish Physiol Biochem 20, 125-134.

Planas, M., Cunha, I., 1999. Larviculture of marine fish: problems and perspectives. Aquaculture 177, 171-190.

Poirier, H., Mathieu, Y., Besnard, P., Bernard, A., 1997. Intestinal lipid esterification and aging in mice and rats. Comp. Biochem. Physiol. 116, 253-260.

Pousão-Ferreira, P., Morais, S., Dores, E., Narciso, L., 1999. Eggs of gilthead seabream Sparus aurata L. as a potential enrichment product of Brachionus sp. in the larval rearing of gilthead seabream Sparus aurata L. Aquac. Res. 30, 751-758.

Rainuzzo, J.R., Reitan, K.I., Olsen, Y., 1994. Effect of short- and long-term lipid enrichment on total lipids, lipid class and fatty acid composition in rotifers. Aquacult. Int. 2, 19-32.

Rainuzzo, J.R., Reitan, K.I., Olsen, Y., 1997. The significance of lipids at early stages of marine fish: a review. Aquaculture 155, 103-115.

Reinecke, M., Muller, C., Segner, H., 1997. An immunohistochemical analysis of the ontogeny, distribution and coexistence of 12 regulatory peptides and serotonin in endocrine cells and nerve fibers of the digestive tract of the turbot, Scophthalmus maximus (teleostei). Anat. Embryol. 195, 87-101.

Ribeiro, L., Sarasquete, C., Dinis, M.T., 1999a. Histological and histochemical development of the digestive system of Solea senegalensis (Kaup, 1858) larvae. Aquaculture 171, 293-308.

Ribeiro, L., Zambonino Infante, J.L., Cahu, C., Dinis, M.T., 1999b. Development of digestive enzymes in larvae of Solea senegalensis, Kaup 1858. Aquaculture 179, 465-473.

Rodríguez, C., Pérez, J.A., Izquierdo, M.S., Cejas, J.R., Bolaños, A., Lorenzo, A., 1996. Improvement of the nutritional value of rotifers by varying the type and concentration of oil and the enrichment period. Aquaculture 147, 93-105.

Rojas-García, C.R., Rønnestad, I., 2002. Cholecystokinin and tryptic activity in the gut and body of developing Atlantic halibut (Hippoglossus hippoglossus): evidence for participation in the regulation of protein digestion. J. Fish Biol. 61, 973-986.

Rust, M.B., 2002. Nutritional Physiology. In: Halver, J.E., Hardy, R.W. (Eds.), Fish Nutrition. Academic Press, USA, pp. 367-452.

Ryer, C.H., Boehlert, G.W., 1983. Feeding chronology, daily ration, and the effects of temperature upon gastric evacuation in the pipefish, Syngnathus fuscus. Environ. Biol. Fish. 9, 301-306.

Salhi, M., Hernández-Cruz, C.M., Bessonart, M., Izquierdo, M.S., Fernández-Palacios, H., 1999. Effect of different dietary polar lipid levels and different n-3 HUFA content in polar lipids on gut and liver histological structure of gilthead seabream (Sparus aurata) larvae. Aquaculture 179, 253-263.

Santinha P.J.M., Medale F., Corraze G., Gomes E.F.S., 1999. Effects of the dietary protein : lipid ratio on growth and nutrient utilization in gilthead seabream (Sparus aurata L.). Aquacult. Nutr. 5, 147156.

Sargent, J., Henderson, R.J., Tocher, D.R., 1989. The lipids. In: Halver, J.E. (Eds.), Fish Nutrition. Academic Press, London, UK, pp. 154-218.

Sargent, J.R., McEvoy, L.A., Bell, J.G., 1997. Requirements, presentation and sources of polynsaturated fatty acids in marine fish larval feeds. Aquaculture 155, 117-128.

Sargent, J.R., McEvoy, L.A., Estevez, A., Bell, G., Bell, M., Henderson, J., Tocher, D., 1999. Lipid nutrition of marine fish during early development: current status and future directions. Aquaculture 179, 217-229.

Segner, H., Storch, V., Reinecke, M., Kloas, W., Hanke, W., 1994. The development of functional digestive and metabolic organs in turbot, Scophthalmus maximus. Mar. Biol. 119, 471-486.

Singer, M.V., 1987. Pancreatic secretory response to intestinal stimulants: a review. Scand. J. Gastroent. 22 (suppl 139), 1-13. 
Sire, M.-F., Vernier, J.-M., 1981. Étude ultrastructurale de la synthèse de chylomicrons au cours de l'absorption intestinale des lipides chez la Truite. Influence de la nature des acides gras ingérés. Biol. Cellulaire 40, 47-62.

Sire, M.-F., Lutton, C., Vernier, J.-M., 1981. New views on intestinal absorption of lipids in teleostean fishes: an ultrastructural and biochemical study in the rainbow trout. J. Lipid Res. 22, 81-94.

Skalli, A., Hidalgo, M.C., Abellán, E., Arizcun, M., Cardenete, G., 2004. Effects of the dietary protein/lipid ratio on growth and nutrient utilization in common dentex (Dentex dentex L.) at different growth stages. Aquaculture 235, 1-11.

Spannagel, A.W., Nakano, I., Tawil, T., Chey, W.Y., Liddle, R.A., Green, G.M., 1996. Adaptation to fat markedly increases pancreatic secretory response to intraduodenal fat in rats. Am. J. Physiol. Gastr. L. 33, G128-G135.

Sæther, B.-S., Jobling M., 2001. Fat content in turbot feed: influence on feed intake, growth and body composition. Aquac. Res. 32, 451-458.

Tocher, D.R., Sargent, J.R., 1984. Studies on triacylglycerol, wax ester and sterol ester hydrolases in intestinal caeca of Rainbow trout (Salmo gairdneri) fed diets rich in triacylglycerols and wax esters. Comp. Biochem. Physiol. 77B, 561-571.

Tso, P., Fujimoto, K., 1991. The absorption and transport of lipids by the small intestine. Brain Res. Bull. 27, 477-482.

Vernier, J.-M., Sire, M.-F., 1986. Is the Golgi apparatus the obligatory final step for lipoprotein secretion by intestinal cells ? Tissue Cell 18, 447-460.

Walford, J., Lam, T.J., 1993. Development of digestive tract and proteolytic enzyme activity in seabass (Lates calcarifer) larvae and juveniles. Aquaculture 109, 187-205.

Werner, R.G., Blaxter, J.H.S., 1980. Growth and survival of larval herring (Clupea harengus) in relation to prey density. Can. J. Fish. Aquat. Sci. 37, 1063-1069.

Wicker, C., Puigserver, A., 1989. Changes in mRNA levels of rat pancreatic lipase in the early days of consumption of a high-lipid diet. Eur. J. Biochem. 180, 563-567.

Yamamoto, T., Shima, T., Unuma, T., Shiraishi, M., Akiyama, T., Tabata, M., 2000. Voluntary intake of diets with varying digestible energy contents and energy sources, by juvenile rainbow trout Oncorhynchus mykiss, using self-feeders. Fish. Sci. 66, 528-534.

Zambonino Infante, J.L., Cahu, C.L., 1999. High dietary lipid levels enhance digestive tract maturation and improve Dicentrarchus labrax larval development. J. Nutr. 129, 1195-1200.

Zambonino Infante, J.L., Cahu, C.L., 2001. Ontogeny of the gastrointestinal tract of marine fish larvae. Comp. Biochem. Physiol. 130C, 477-487. 

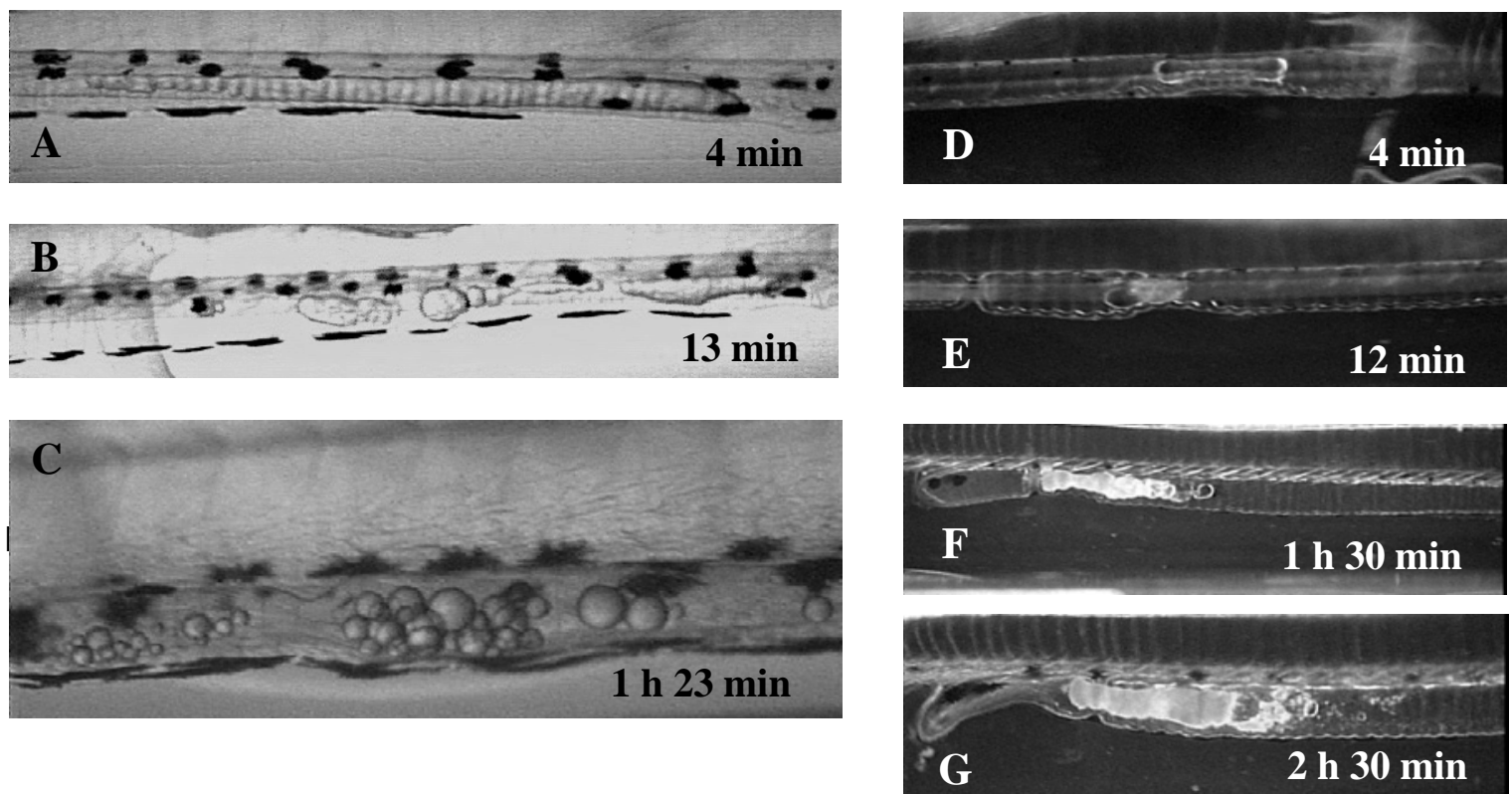

Fig. 1. Lipid emulsification (mechanical and chemical action) in the midgut of herring (Clupea harengus) larvae, at different times after tube feeding $50.6 \mathrm{nl}(\mathrm{A}-\mathrm{C})$ or $9.2 \mathrm{nl}(\mathrm{D}-\mathrm{G})$ of triolein (adapted from Morais et al., 2005a). 


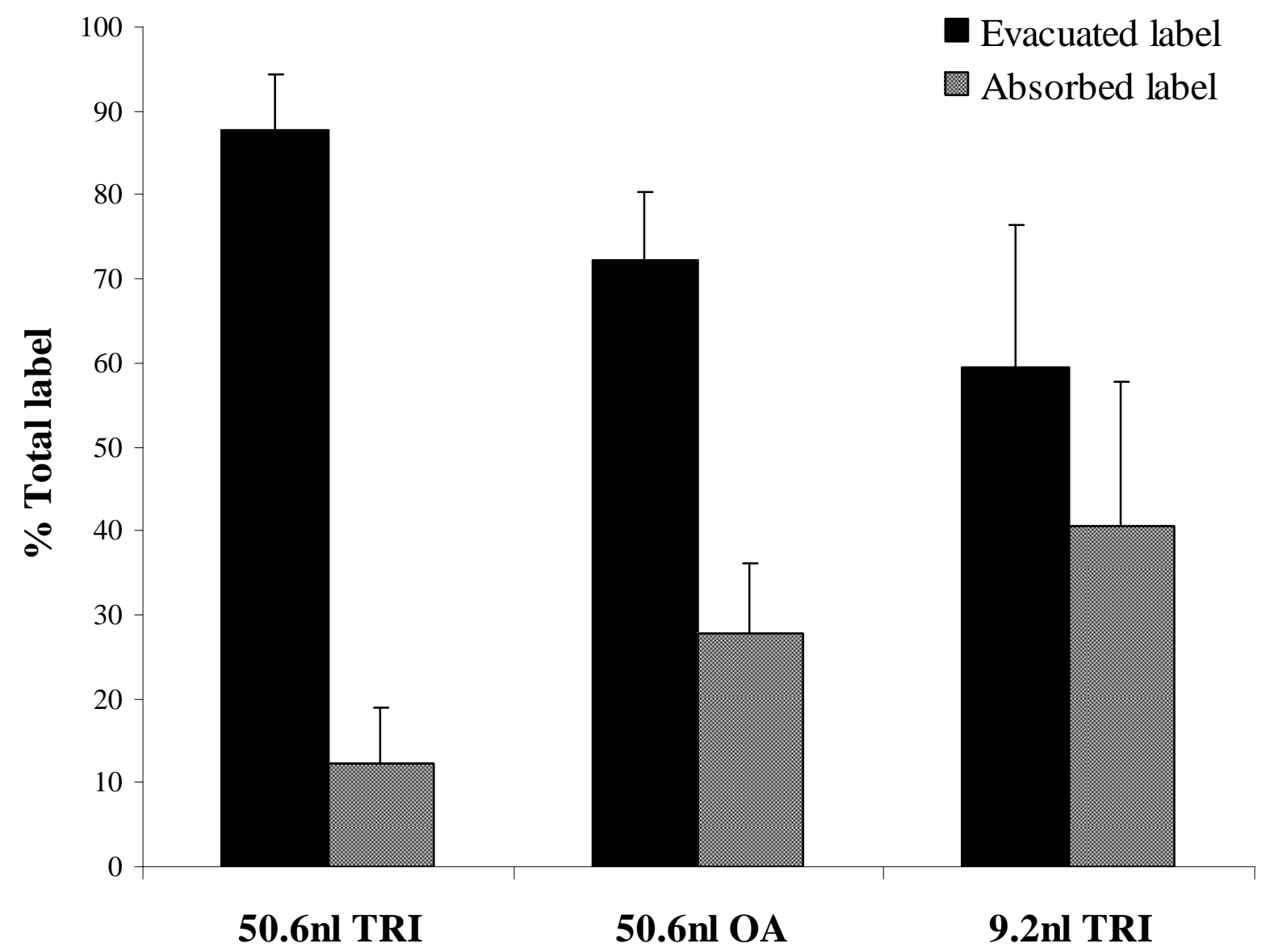

Fig. 2. Percentage of evacuated or absorbed (retained in body and gut tissues + catabolised) label, 24 $\mathrm{h}$ after tube feeding Atlantic herring (Clupea harengus) larvae with $50.6 \mathrm{nl}$ of triolein (TRI), 50.6nl of oleic acid mixture (OA) or 9.2nl of TRI (adapted from Morais et al., 2005a). 

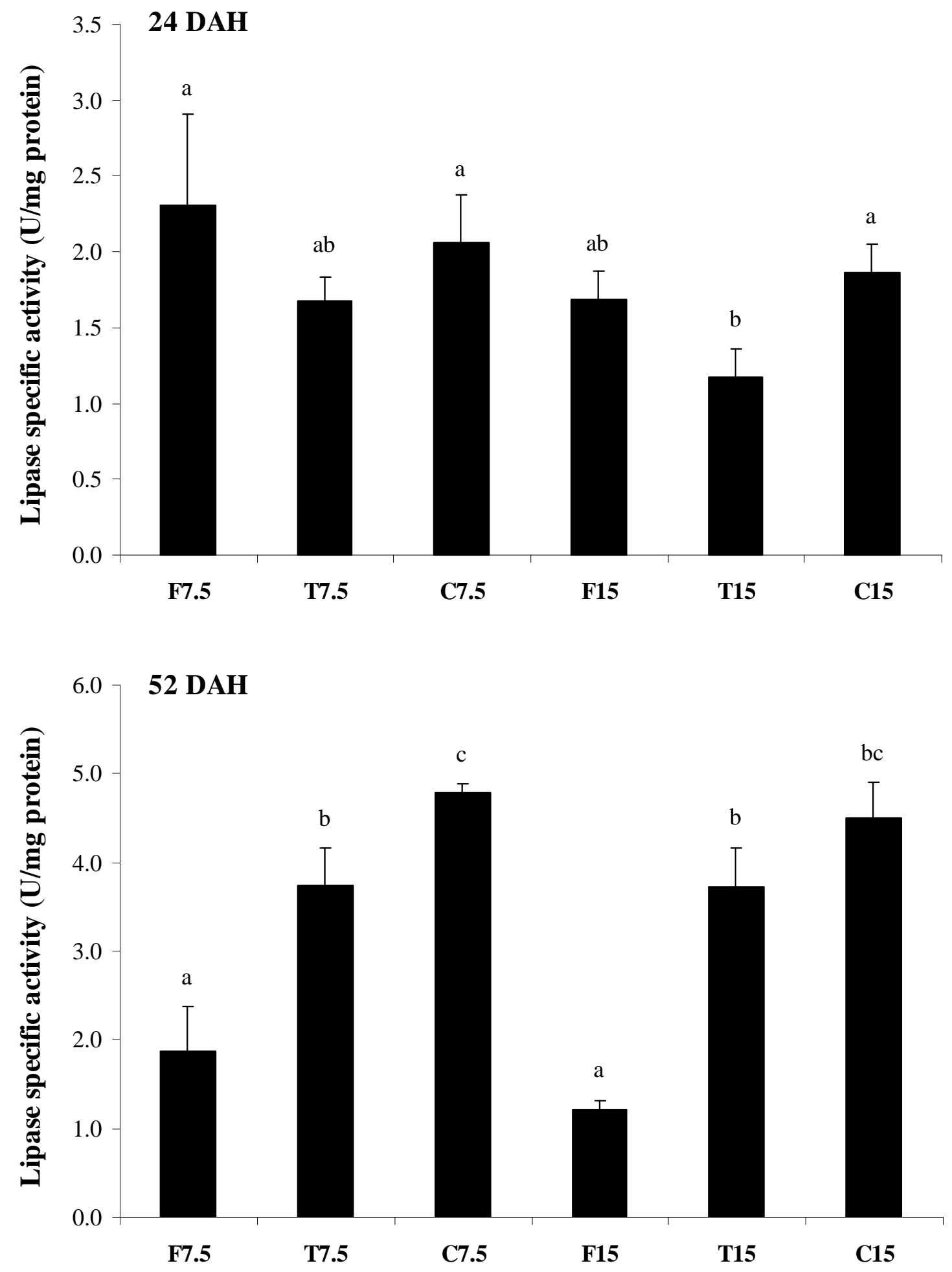

Fig. 3. Lipase specific activity (U/mg protein) of 24 and 52 days after hatching (DAH) seabass (Dicentrarchus labrax) fed a formulated diet containing $7.5 \%$ or $15 \%$ of fish oil (F7.5 and F15), triolein (T7.5 and T15) or coconut oil (C7.5 and C15). Columns with different letters are significantly different $(P<0.05$, one-way ANOVA) (from Morais et al., 2004a). 


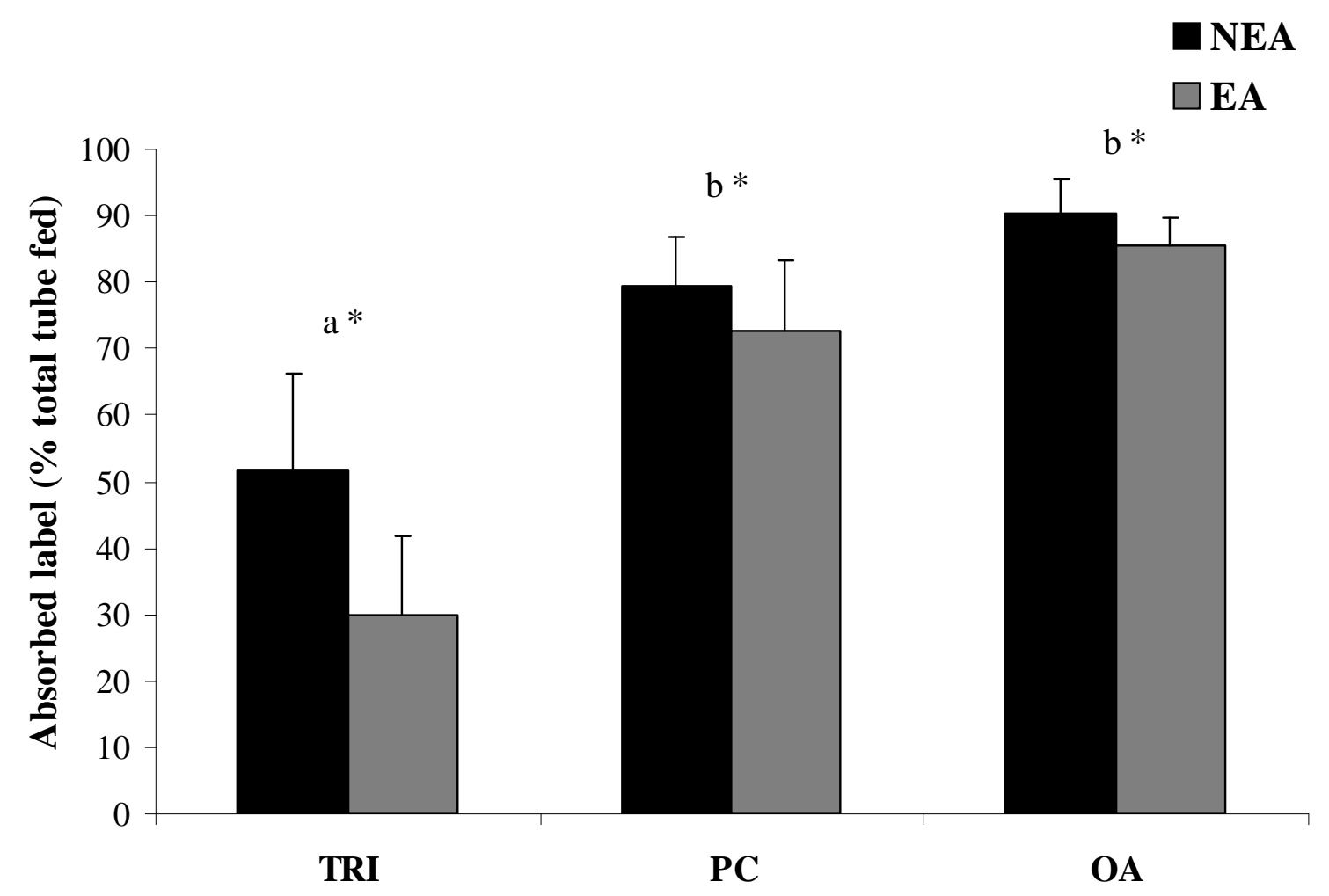

Fig. 4. Percentage of absorbed label (total tube fed minus evacuated), $24 \mathrm{~h}$ after tube feeding Senegalese sole (Solea senegalensis) with one of several ${ }^{14} \mathrm{C}$-labelled lipids (triolein; TRI or L-3phosphatidylcholine 1,2, di-oleoyl; PC) or a free fatty acid (oleic acid; OA). Larvae were reared on non enriched Artemia (NEA) or Artemia enriched on a soybean oil emulsion (EA) from 16 to 32 days after hatching (DAH) and prior to tube feeding, at $32 \mathrm{DAH}$, larvae were fed a meal of the corresponding treatment - NEA or EA. Asterisks represent significant differences between the NEA and EA treatments (two-way ANOVA, $p=0.001$ ), while different letters indicate significant differences between the tube fed labels (one-way ANOVA, p<0.001) (adapted from Morais et al., 2005b). 


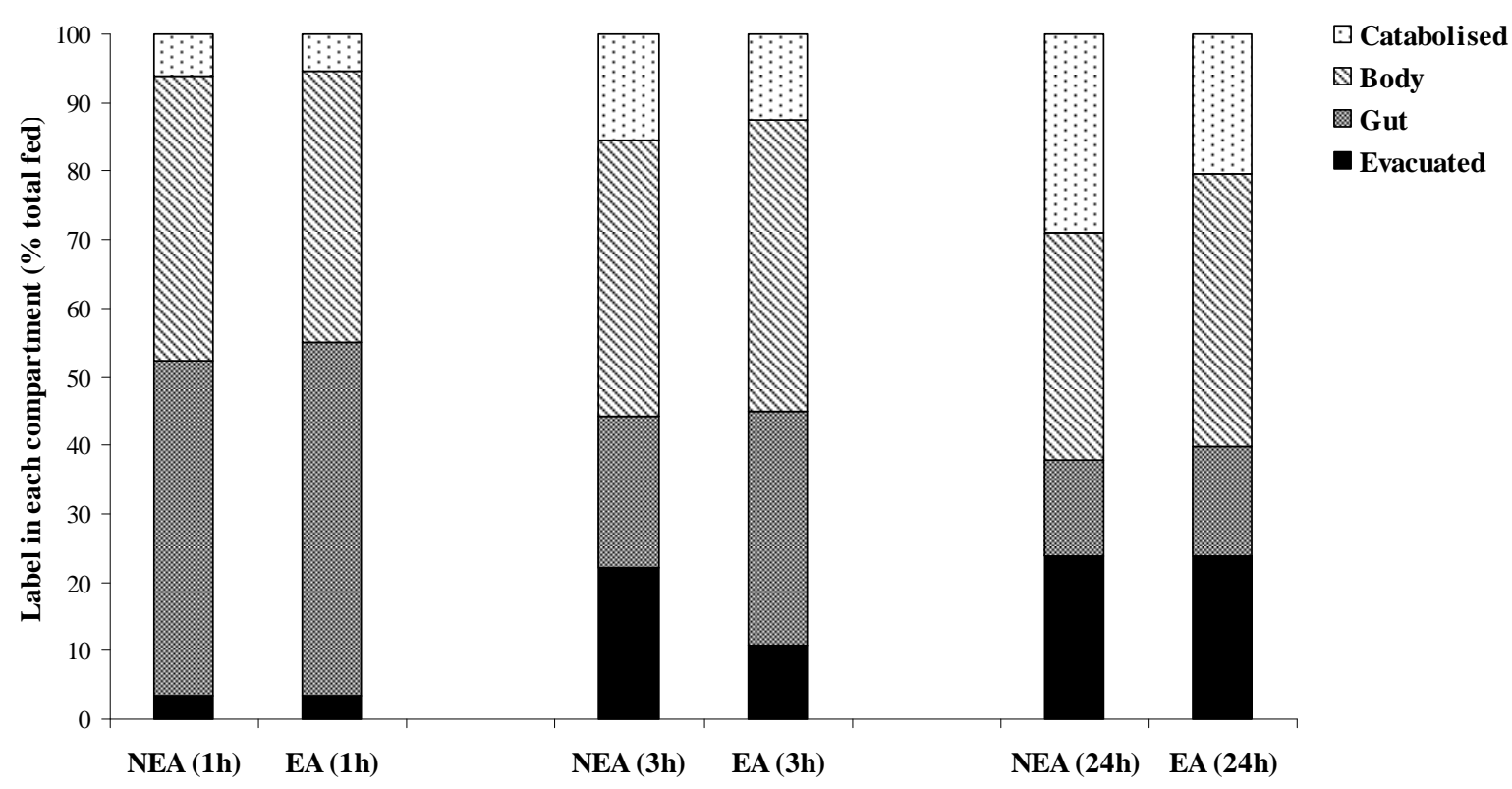

Fig. 5. Label in each compartment (\% of total label fed) of 27 days after hatching Senegalese sole (Solea senegalensis) larvae, at 1, 3 and $24 \mathrm{~h}$ after feeding on either non enriched Artemia (NEA) or Artemia enriched on a soybean oil emulsion (EA) that were radiolabelled with a $\left[\mathrm{U}^{14} \mathrm{C}\right]$ protein hydrolysate (92-93\% of label incorporated in the TCA precipitate fraction - mostly protein). Larvae were reared on the experimental treatments (NEA or EA) from 16 DAH onwards (adapted from Morais et al., 2005c). 

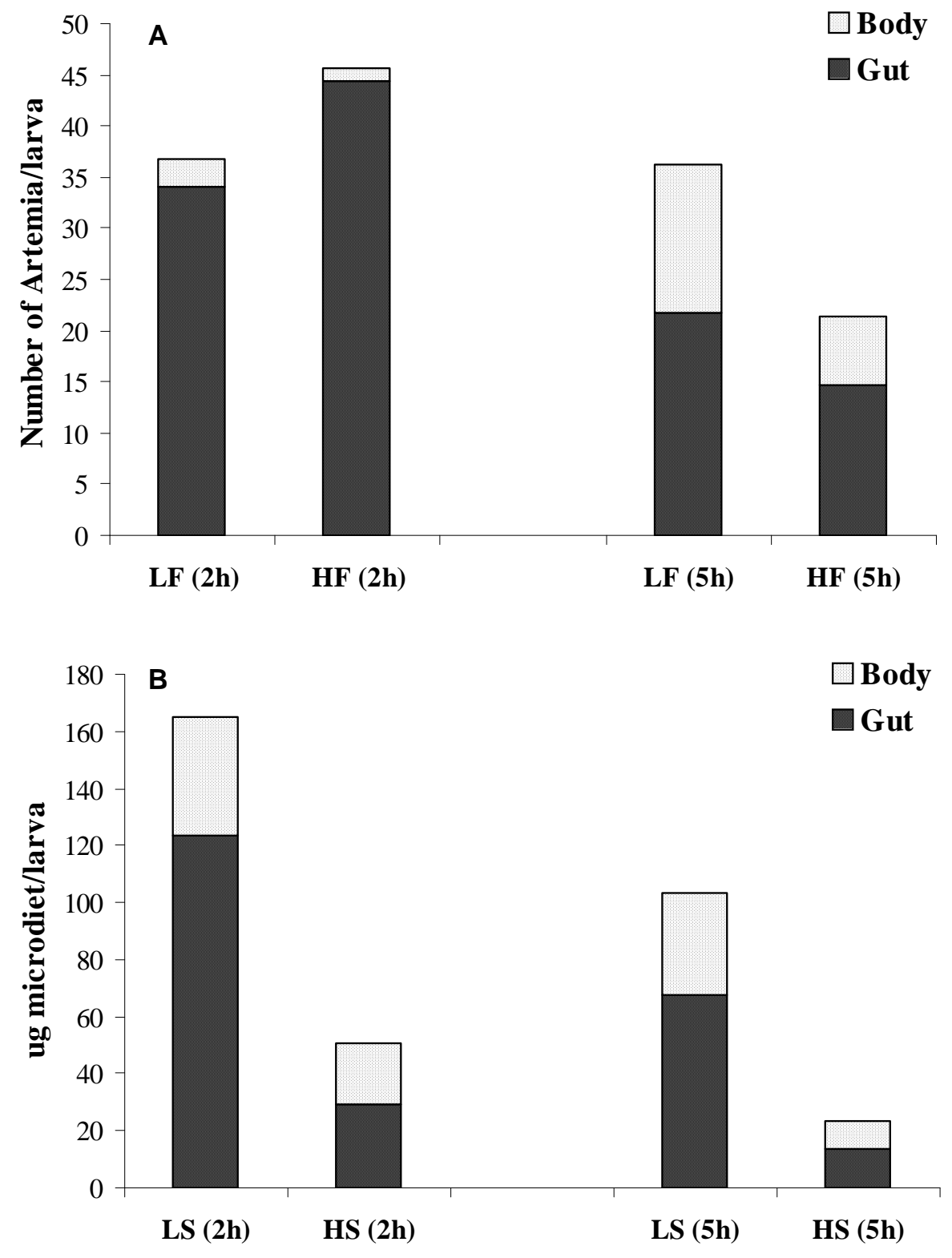

Fig. 6. Food intake of seabream (Sparus aurata) larvae, 2 and $5 \mathrm{~h}$ after feeding on a ${ }^{14} \mathrm{C}$-radiolabelled diet, using a cold chase approach. Larvae were allowed to feed on the labeled diet during $2 \mathrm{~h}$, after which a group of larvae (25-30 larvae, in triplicate) were sampled. The remaining radioactive diet and much of the water was siphoned and fresh seawater with non-labelled treatment diet was added. Assuming that the subsequent rate of clearance of radioactivity in the gut is influenced by food intake rate and absorption from the lumen, a higher decrease in the amount of radioactive diet in the gut at 5 $\mathrm{h}$ after start feeding (or $3 \mathrm{~h}$ after cold chase) indicates a higher ingestion and/or faster absorption. A Larvae at 33 days after hatching (DAH) fed Artemia labelled with $\left[1-{ }^{14} \mathrm{C}\right]$ oleic acid-liposomes and enriched on either a low or high dose of fish oil emulsion (LF and HF). B - Larvae at 32 DAH fed [1${ }^{14} \mathrm{C}$ ]oleic acid-microdiets containing either low or high levels of soybean oil (LS and HS) (adapted from Morais et al., 2006b). 